Trends

\title{
Progress in correlation spectroscopy at ultra-fast magic-angle spinning: Basic building blocks and complex experiments for the study of protein structure and dynamics
}

\author{
Jean-Philippe Demers, Veniamin Chevelkov, Adam Lange* \\ Department of NMR-based Structural Biology, Max Planck Institute for Biophysical Chemistry, Am Fassberg 11, 37077 Göttingen, Germany
}

\section{A R T I C L E I N F O}

\section{Article history:}

Received 4 May 2011

Received in revised form

21 July 2011

Available online 3 August 2011

Keywords:

Solid-state NMR

Protein structure

Protein dynamics

Ultra-fast magic-angle spinning

Paramagnetic proteins

\begin{abstract}
A B S T R A C T
Recent progress in multi-dimensional solid-state NMR correlation spectroscopy at high static magnetic fields and ultra-fast magic-angle spinning is discussed. A focus of the review is on applications to protein resonance assignment and structure determination as well as on the characterization of protein dynamics in the solid state. First, the consequences of ultra-fast spinning on sensitivity and sample heating are considered. Recoupling and decoupling techniques at ultra-fast MAS are then presented, as well as more complex experiments assembled from these basic building blocks. Furthermore, we discuss new avenues in biomolecular solid-state NMR spectroscopy that become feasible in the ultrafast spinning regime, such as sensitivity enhancement based on paramagnetic doping, and the prospect of direct proton detection.
\end{abstract}

(c) 2011 Elsevier Inc. All rights reserved.

\section{Contents}

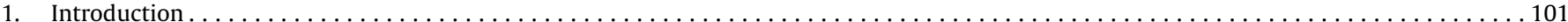

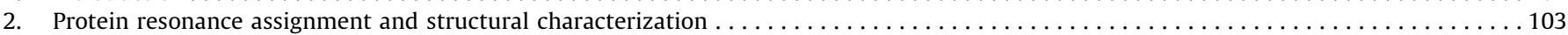

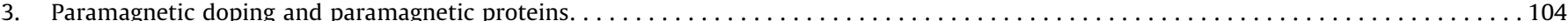

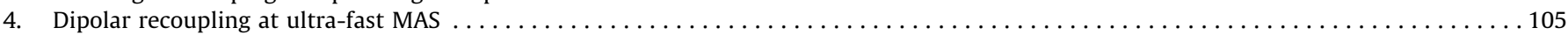

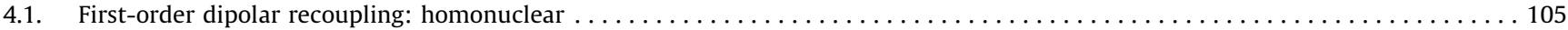

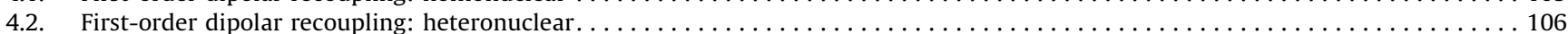

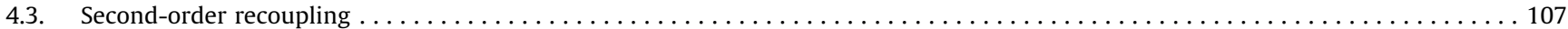

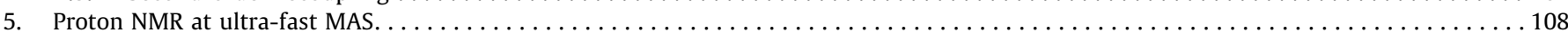

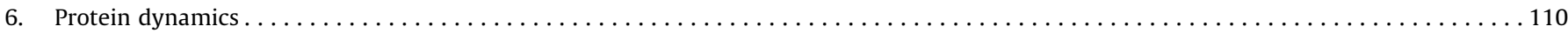

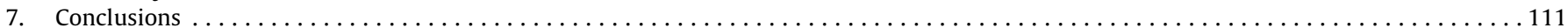

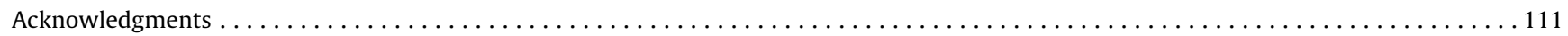

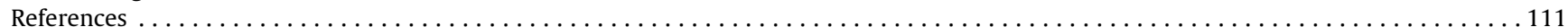

\section{Introduction}

The last decade has seen tremendous technological and methodological developments in the field of magic-angle spinning (MAS) solid-state NMR (ssNMR) [1,2]. These developments have allowed for the structural characterization of many samples of high biological interest: microcrystalline proteins, amyloid fibrils, oligomeric assemblies, and membrane proteins in a native-like

\footnotetext{
* Corresponding author.

E-mail address: adla@nmr.mpibpc.mpg.de (A. Lange).
}

environment. Part of those developments can be attributed to the widespread adoption of high static magnetic fields.

At the same time, fast spinning MAS probe-heads of a new generation have been developed and are now commercially available. This promises to further improve the resolution and sensitivity of biological solid-state NMR. Additionally in the ultrafast spinning regime, fundamentally new applications have become feasible. In this review, we will discuss these recent improvements: the study of paramagnetic metal binding centers, new methods for resonance assignment and collection of longrange distance restraints, proton detection at ultra-fast MAS, and the study of protein dynamics. 
It should be noted that complementary information to the current article is available. In a review by Anne Lesage [1], the advantages of fast MAS are presented in the context of organic solid materials along with recent advances in structural investigations. The mechanical aspect of fast rotation and the impact of coil dimension on radio-frequencies (RF) are discussed in a recent chapter of the Encyclopedia of Magnetic Resonance by Ago Samoson and coworkers [3]. Another chapter of the Encyclopedia of Magnetic Resonance by Donghua $\mathrm{H}$. Zhou [4] introduces fast MAS in combination with proton detection and paramagnetic doping.

In this review, we will distinguish between three regimes of spinning frequencies: low MAS below $20 \mathrm{kHz}$, fast MAS between 20 and $40 \mathrm{kHz}$, and ultra-fast MAS above $40 \mathrm{kHz}$. So far, ultra-fast MAS can be attained with rotors of reduced size: $40-50 \mathrm{kHz}$ MAS for rotors of outer diameter (o.d.) $1.8 \mathrm{~mm}$ and $1.6 \mathrm{~mm}$, and $60-$ $70 \mathrm{kHz}$ MAS for rotors of o.d. $1.3 \mathrm{~mm}$ and $1.2 \mathrm{~mm}$. More recently, MAS frequencies of up to $80 \mathrm{kHz}$ have been reached by rotors with an o.d. of $1.0 \mathrm{~mm}$ (JEOL, Japan) [5]. For comparison purposes, the characteristics of some commercially available rotors (Fig. 1a) are summarized in Table 1 . The reduction in rotor dimensions has important repercussions with respect to sensitivity, RF performance, and sample heating.

In NMR, sensitivity per unit square root time $(S / N)_{t}$, or more simply sensitivity, is generally defined as the signal to noise ratio $(S / N)$ in the frequency domain per unit square root time (Eq. (1)) [7]. It is closely related to the time-domain $S / N$ directly following a $90^{\circ}$ pulse, which has been described in a closed-form expression by Hoult and Richards [8]. The signal part (Eq. (2)) depends notably on the sample volume $V_{\text {sample }}$ and on the coil sensitivity $\left(B_{1}\right)_{x y}$, defined as the magnitude of the transverse magnetic field induced in the sample by a current of $1 \mathrm{~A}$ flowing in the RF coil [9]. In ultra-fast MAS rotors, the large reduction in active volume expectedly results in a reduction of the absolute signal. Contrarily, for a solenoid coil, the coil sensitivity $\left(B_{1}\right)_{x y}$ is improved with smaller diameters (Eq. (3)), reflecting an improvement of the filling factor. The noise amplitude $\sigma_{\text {noise }}$ (Eq. (4)) depends on the spectral bandwidth $\Delta f$, and resistance losses $R_{\text {noise }}$ (conductive, magnetic, and dielectric losses) which are mostly dictated by the wire geometry of the receiver coil. If we make the fair assumption that the height to radius ratio is conserved among the different coils, then noise amplitude is unaffected by the rotor diameter. The outcome is that the absolute $S / N$ is roughly proportional to the rotor diameter, as described in Refs. [9,10]. The $S / N$ relative to the amount of material is improved in rotors of smaller diameter, which is advantageous for mass-limited samples (Fig. 1b).

$(S / N)_{t} \equiv \frac{S}{\sigma_{\text {noise }} \sqrt{T_{\text {tot }}}}$
$S$ is the frequency domain signal peak amplitude, $\sigma_{\text {noise }}$ is the frequency domain R.M.S. noise amplitude, and $T_{\text {tot }}$ is the total experimental time.

$(S / N)_{t} \propto V_{\text {sample }}\left(B_{1}\right)_{x y} M_{0} \omega_{0} K$

$\left(B_{1}\right)_{x y}$ is the sensitivity of the RF coil, $M_{0}$ is the initial magnetization, $V_{\text {sample }}$ is the sample volume, $\omega_{0}$ is the Larmor frequency, and $K$ is the $\mathrm{RF}$ inhomogeneity factor.

$\left(B_{1}\right)_{x y}=\frac{\mu_{0} n}{2} \frac{1}{\sqrt{r_{\text {coil }}^{2}+\left((1 / 2) h_{\text {coil }}\right)^{2}}}$

$\mu_{0}$ is the vacuum permeability ( $4 \pi \times 10^{-7} \mathrm{NA}^{-2}$ ), $n$ is the number of wire turns in the solenoid, and $r_{\text {coil }}$ and $h_{\text {coil }}$ are the radius and height of the solenoid coil, respectively.

$\sigma_{\text {noise }}=\sqrt{4 k_{B} T_{c} R_{\text {noise }} \Delta f}$

$k_{B}$ is the Boltzmann constant, $T_{C}$ is the coil temperature, $R_{n o i s e}$ is the resistance losses, and $\Delta f$ is the bandwidth of the receiver.

The high coil sensitivity $\left(B_{1}\right)_{x y}$ also entails high RF performance for ultra-fast MAS probe-heads, meaning that large RF fields can be generated by the coil without requiring a large input power from the amplifiers [4]. However, such strong RF irradiation has the drawback of depositing a high amount of energy in the sample. For instance, rapidly oscillating electric fields will bring free charge carriers in motion and will induce the realignment of molecular dipoles [11]. The resistance of the environment to such motion draws energy from the electric field; a sample with high resistance is termed "lossy". The situation is particularly critical in the study of biological samples $[12,13]$, which are fragile and often preserved in ionic buffers or in a lipid environment. Eventually, the heat contributed can lead to irremediable alteration of the sample, for instance degradation, denaturation, or aggregation. Another cause of concern is the effect of heating on experimental results. RF absorption and heat dissipation depend on numerous factors, crippling reproducibility of results if different pulse sequences, sample conditions, or instruments are

Table 1

Comparison of MAS rotor sizes.

Data according to Ref. [6].

\begin{tabular}{lllllllll}
\hline Outer diameter $(\mathrm{mm})$ & 7 & 4 & 3.2 & 2.5 & 2.5 & 1.3 & 1.6 & 1.2 \\
Inner diameter $(\mathrm{mm})$ & 5.6 & 3.0 & 2.2 & 1.7 & 1.3 & 0.9 & & \\
Sample volume $^{\mathrm{a}}(\mu \mathrm{L})$ & 246 & 70 & 30 & 14 & 8 & 1.7 & 8.1 & 1.2 \\
Max. spinning frequency $(\mathrm{kHz})$ & 7 & 15 & 24 & 35 & 35 & 67 & 45 & 65 \\
Manufacturer & \multicolumn{3}{c}{ Bruker Biospin } & & & & \multicolumn{7}{c}{ Agilent }
\end{tabular}

${ }^{a}$ For Bruker Biospin rotors, the sample volume refers to the active sample volume inside the NMR RF coil (data provided by Dr. Frank Engelke, Bruker Biospin, Germany); for Agilent Technologies, it refers to the total sample volume. a

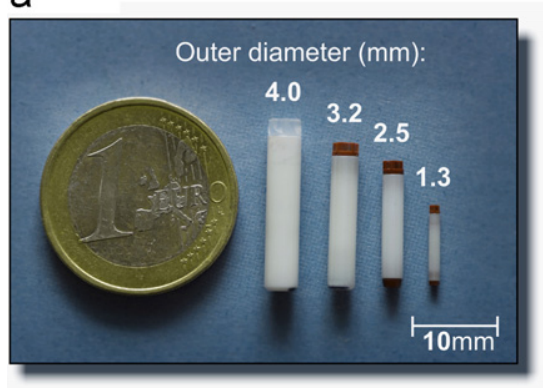

b

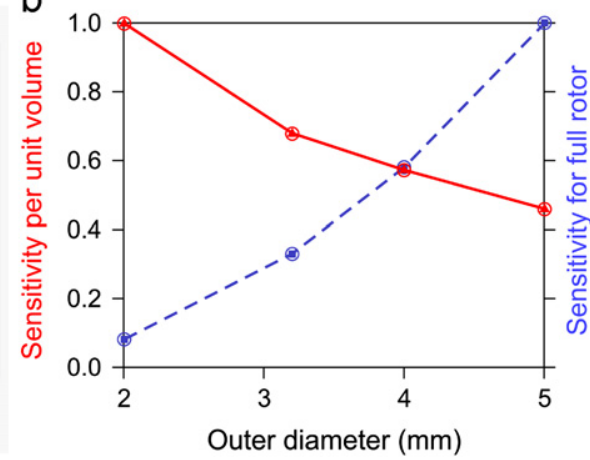

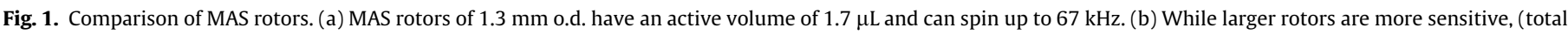
sensitivity $(S / N)_{t}$, blue) small rotor sizes exhibit a higher sensitivity per unit volume $\left((S / N)_{t} / V_{\text {sample }}\right.$, red).

Figure adapted from Ref. [15]. 
used. The heterogeneity of spectroscopic observables due to spatial temperature gradients is exacerbated at strong RF fields and can persist for several hundreds of milliseconds after the heating pulse [13]. Small rotors are beneficial in this respect, as temperature gradients due to irradiation increase as the fourth power of the coil diameter [14].

To overcome the transient heat deposition by RF, one strategy is the development of pulse sequences requiring minimal amounts of irradiation power. Another strategy is to change the design of the RF coil in order to reduce the generation of timevarying electric fields during irradiation. Multiple designs have been introduced to replace or improve the typically employed solenoidal coils and are discussed in a review by Christopher V. Grant and coworkers [16]. Designs which have been combined with MAS include the scroll coil [17], the cross coil/solenoid [14], the $\mathrm{Z}$ coil [18], the loop-gap loaded coil [13], and "low-E" coils [19]. Both of those strategies directly improve spectral resolution since they allow longer acquisition times to be tolerated.

An additional cause of heating in MAS solid-state NMR is the power loss due to friction between the pressured gas and the bearings. The power loss is proportional to the square of the spinning frequency [20] and can lead to temperature increases of $40-60{ }^{\circ} \mathrm{C}$ at $60 \mathrm{kHz}$ MAS in comparison with the static case [4]. In contrast to RF heating, frictional heating remains uniform over time, although non-uniform spatially. It is likely that cooling gas remedies frictional heating more effectively than it does RF heating [14]. Because of the large temperature difference, the flow and temperature of the cooling gas have to be gradually adapted during spinning-up and spinning-down of the rotor. For biological samples, a facile temperature calibration can be done on the water ${ }^{1} \mathrm{H}$ signal in combination with internal DSS chemical shift referencing [21].

The effects of high spinning rates are decisive in preserving a competitive sensitivity compared to larger rotors. For resonances with large chemical shift anisotropies, the very fast rotation has the consequence of moving spinning sidebands out of the spectral window, increasing the intensity of the center band $[10,22]$. Homonuclear dipolar couplings are as well greatly reduced (see Fig. 8 and Section 5 on Proton NMR at ultra-fast MAS), resulting in narrower and more intense lines [23]. Pulse sequences developed for ultra-fast MAS promise further improvements in sensitivity and resolution by employing four complementing strategies: (1) increased transfer to cross-peaks during magnetization mixing steps, (2) reduced decay of spin-locked and transverse magnetization, (3) low-power sequences which enable fast recycling and long acquisition times, (4) proton detection. The application of ultra-fast MAS techniques to the study of proteins and other biomolecules is discussed in the following sections.

\section{Protein resonance assignment and structural characterization}

Achieving a complete assignment of the NMR signals constitutes the first step in structural studies using solid-state NMR and still stands as a major obstacle in obtaining site-specific structural information. Usually, a combination of two-dimensional correlation spectra is required for the sequential resonance assignment
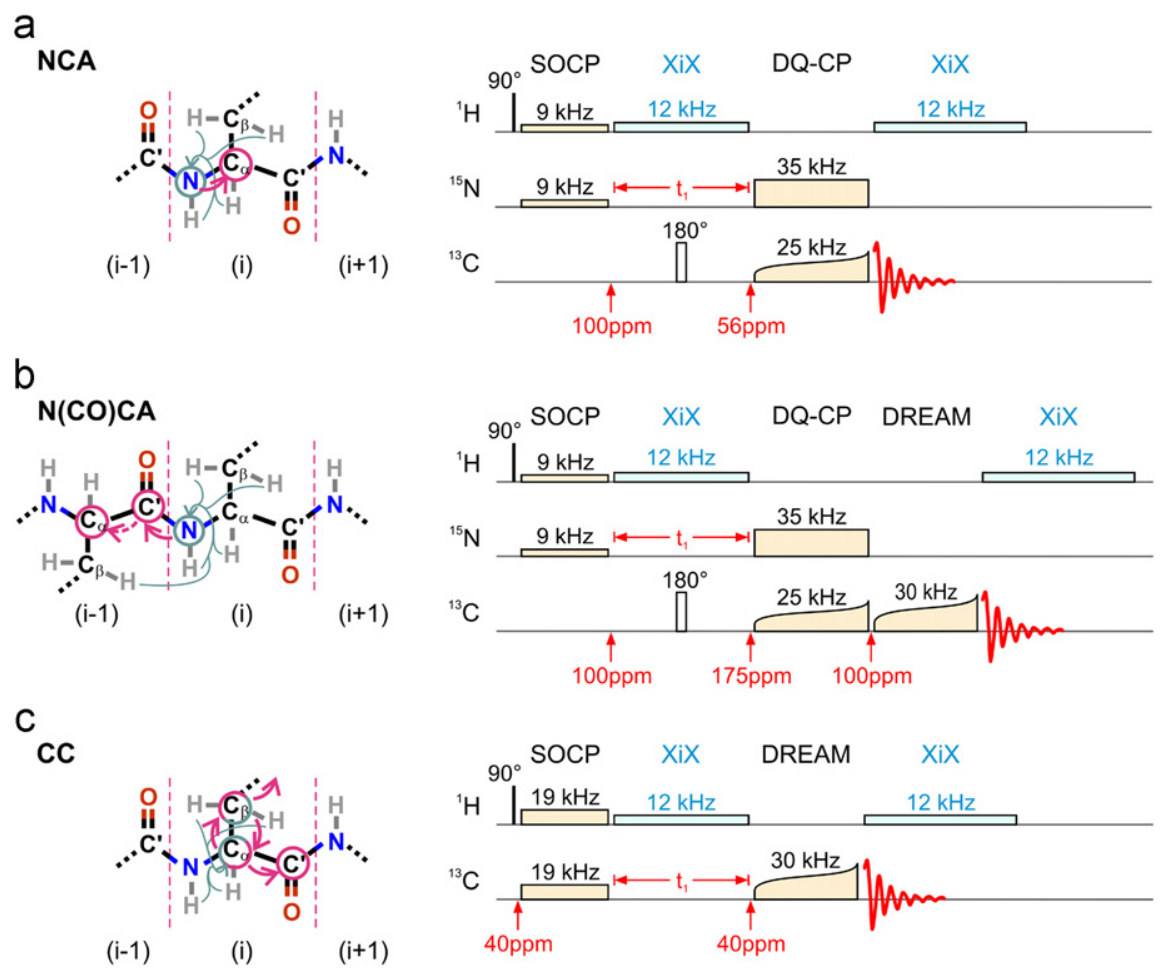

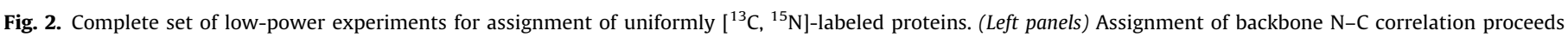

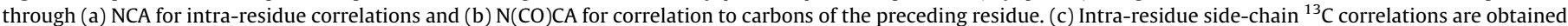

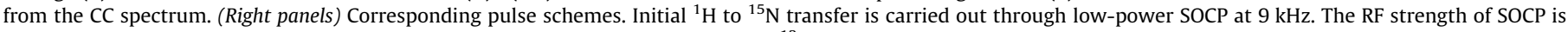

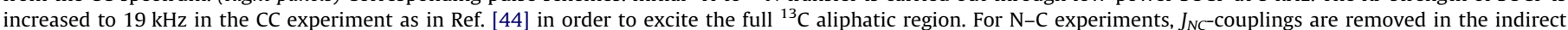

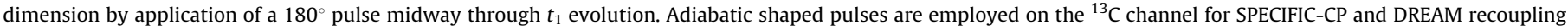

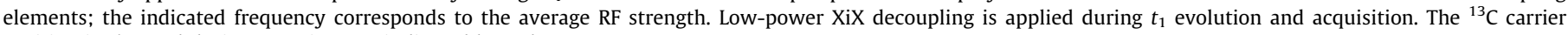
position is changed during experiments, indicated by red arrows.

Figure adapted from Ref. [41]. 
of uniformly $\left[{ }^{13} \mathrm{C},{ }^{15} \mathrm{~N}\right.$-labeled proteins. For larger systems, often assignment ambiguities remain and 3D or even 4D solid-state NMR experiments need to be performed [24-27].

At low-MAS frequencies $(\sim 7-13 \mathrm{kHz})$, the standard repertoire of experiments for protein resonance assignment consists of homonuclear ${ }^{13} \mathrm{C}-{ }^{13} \mathrm{C}$ correlation experiments such as protondriven spin-diffusion (PDSD) [28] or alternatively RAD/DARR $[29,30]$ as well as heteronuclear ${ }^{15} \mathrm{~N}-{ }^{13} \mathrm{C}$ correlation experiments such as NCACX or NCOCX. In the latter case, the transfer from $\mathrm{C}_{\alpha}$ or $C^{\prime}$ to CX often relies on PDSD or DARR. However, PDSD and DARR become ineffective at high spinning frequencies and at high static magnetic fields. In the case of ultra-fast MAS, the MIRROR [31], RESORT [32], and PARIS [33,34] experiments can be used analogously to PDSD and DARR (see Section 4 on Dipolar recoupling at ultra-fast MAS). As well, Hou and coworkers reported homonuclear ${ }^{13} \mathrm{C}-{ }^{13} \mathrm{C}$ spin-diffusion experiments based on R-symmetry sequences [35]. They found that such experiments work well at fast MAS frequencies of $40 \mathrm{kHz}$ where conventional PDSD or DARR experiments already fail.

Several first-order recoupling sequences for ${ }^{13} \mathrm{C}-{ }^{13} \mathrm{C}$ transfer have been introduced which work well at ultra-fast spinning, for example DREAM [36] providing double-quantum transfer, or RFDR [37,38] providing zero-quantum transfer. A general difference between PDSD which is a second-order process and firstorder dipolar recoupling experiments such as DREAM and RFDR is that the latter ones are strongly influenced by dipolar truncation [39]. Here, transfer is restricted to the strongest dipolar couplings present, usually between directly bonded nuclei, e.g. $C_{\alpha}$ and $C_{\beta}$. Relying only on first-order sequences therefore restricts the number of observed correlations. The detection of sequential transfer, for instance between $C_{\alpha}$ nuclei of adjacent residues, feasible with PDSD [40], is therefore difficult to achieve with firstorder recoupling sequences.

Nevertheless, it is in principle possible to compile a set of experiments suitable for the complete resonance assignment of uniformly labeled proteins at ultra-fast MAS. For instance, such a complete set of experiments was introduced by Vijayan et al. and is depicted in Fig. 2 [41]. The set comprises CC, NCA, and N(CO)CA two-dimensional correlation experiments. Applications to ubiquitin and tau paired helical filaments are described in Ref. [41]. After resonance assignments have been obtained, ${ }^{13} \mathrm{C}$ and ${ }^{15} \mathrm{~N}$ chemical shifts can be readily analyzed in terms of secondary structure using secondary chemical shifts [42] or statistical database approaches such as TALOS [43].

Experiments for gathering distance restraints at ultra-fast MAS are still scarce. Since approaches based on PDSD will fail under ultra-fast MAS conditions, other strategies have to be pursued. One successful approach has been presented by Lewandowski et al. [45]. In this study, the authors demonstrated that the PAR experiment works even at an MAS frequency of $65 \mathrm{kHz}$. Application to GB1 yielded highly resolved 2D spectra which allow for the extraction of long-range ${ }^{13} \mathrm{C}-{ }^{13} \mathrm{C}$ proximities.

Another promising approach for the detection of long-range restraints has recently been reported by Huber et al. [46]. This approach relies on the measurement of long-range proton-proton distances in extensively deuterated samples with proton-detected 3D and 4D correlation experiments. The method utilizes DREAM mixing for efficient proton-proton transfer and was applied to a sparsely methyl- and amide-labeled ubiquitin sample. Simultaneously, a very similar approach has also been presented by Linser et al. [47].

Meier and coworkers also demonstrated that ${ }^{3 \mathrm{~h}} J_{N C}$, hydrogenbond scalar couplings can be directly detected at ultra-fast MAS $(55-57 \mathrm{kHz})$ using extensively deuterated samples [48]. The measurement of these sub-Hertz scalar couplings currently remains challenging but the approach is potentially very useful for structural biology applications and could further research on $\beta$-sheet-rich amyloid fibrils.

\section{Paramagnetic doping and paramagnetic proteins}

As previously mentioned, the ultra-fast spinning regime has the advantage that entirely low-power sequences can be applied $[41,49]$. While low-MAS heteronuclear decoupling sequences are a priori viable at faster MAS, an important realization from the beginning of the last decade was that commensurate or improved decoupling performances are realized at low RF powers in the ultra-fast MAS regime [50]. The sequences which are currently considered to offer the best decoupling are low-power XiX [51], low-power TPPM [52], swept low-power TPPM [53], and lowamplitude PISSARRO [54]. In practice, more than one decoupling sequence should be tested, as the relative performance can fluctuate depending on the MAS frequency, static magnetic field $B_{0}$, and on the molecular system, similar to what was investigated at low MAS $[55,56]$.

Since only weak RF fields in the order of $10-20 \mathrm{kHz}$ are used for heteronuclear ${ }^{1} \mathrm{H}$ decoupling, the strain on the instrumentation and the heat deposition are mitigated. Multi-dimensional spectra can be recorded with longer acquisition times and faster repetition rates compared with experiments at low spinning frequencies and high-power decoupling. For instance, an extremely well-resolved band-selective INADEQUATE- $S^{3} E$ spectrum of microcrystalline GB1 is reported in Ref. [57], recorded with maximum acquisition times of $37 \mathrm{~ms}$ in $t_{1}$ and $50 \mathrm{~ms}$ in $t_{2}$ at $60 \mathrm{kHz}$ MAS on a $1 \mathrm{GHz}(23.5 \mathrm{~T})$ spectrometer.

Such low-power approaches for resonance assignment and detection of structural restraints can be combined with paramagnetic optimized relaxation times [58,59]. The recycle delay can then be reduced and the resulting sensitivity enhancement compensates for the loss of sensitivity due the small sample volume of fast-spinning MAS rotors (Fig. 3). For this purpose, paramagnetic dopants such as Cu-EDTA are added in

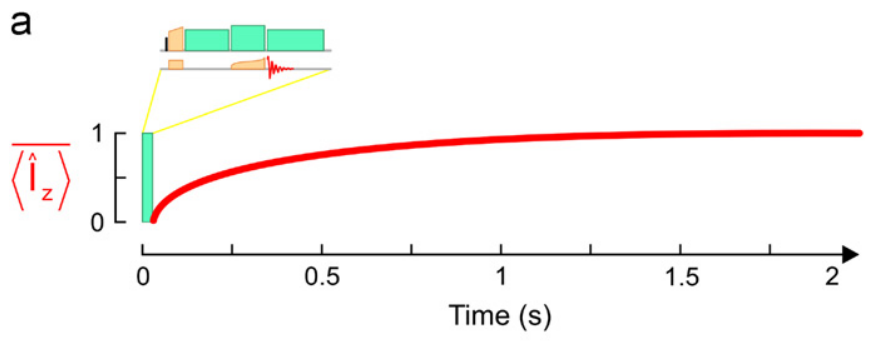

b

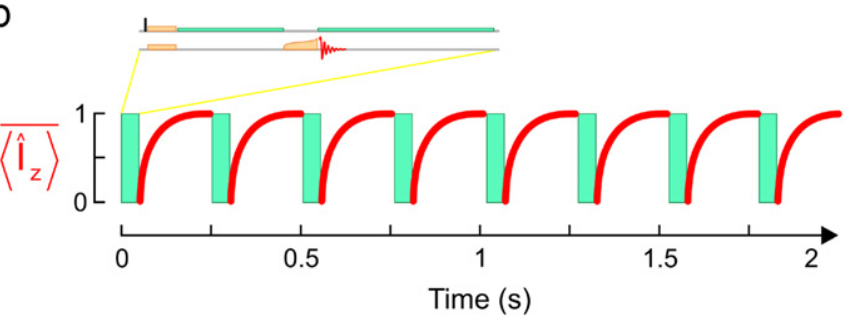

Fig. 3. Fast repetition rates and paramagnetic doping. (a) In traditional acquisition, the duration of the inter-scan delay is dictated by the delay necessary for heat dissipation, and by the recovery rate of proton longitudinal magnetization, as depicted by the red curve. (b) In condensed acquisition, the experiment can be repeated at a faster rate, approximately an order of magnitude faster, owing to the acceleration of ${ }^{1} \mathrm{H}$ longitudinal relaxation rate by paramagnetic dopants. The use of entirely low-power sequences prevents excessive deposition of heat and allows for longer acquisition times, therefore increasing resolution. (For interpretation of the references to color in this figure legend, the reader is referred to the web version of this article.) 
concentrations of $10-250 \mathrm{mM}$. This shortens the ${ }^{1} \mathrm{H}_{1}$ relaxation times down to 50-100 ms [60]. Reif and coworkers have proposed to combine ultra-fast MAS, paramagnetic doping, and deuteration [12]. Nadaud and coworkers have demonstrated that a similar approach comprising 2D and 3D correlation spectra can also be applied to proteins with covalently bound paramagnetic tags [61].

Furthermore, fast recycling experiments can be readily applied to paramagnetic metalloproteins. For example, a $2 \mathrm{D}{ }^{13} \mathrm{C}-{ }^{13} \mathrm{C}$ correlation spectrum of the oxidized, paramagnetic form of human copper zinc superoxide dismutase (SOD) could be acquired with a shortened recycle delay of $500 \mathrm{~ms}$ [62]. Bertini et al. reported the application of ultra-fast MAS and fast recycling protocols to detect residues as close as $5.6 \AA$ from the $\mathrm{Co}^{\mathrm{II}}$ in MMP-12 [63]. This opens the way to characterize the metal coordination environment of metalloproteins by ssNMR which was previously unobservable at lower spinning frequencies due to large and highly anisotropic paramagnetic chemical shifts.

\section{Dipolar recoupling at ultra-fast MAS}

The standard building units for multi-dimensional ssNMR experiments are homonuclear and heteronuclear recoupling sequences, along with periods of evolution where decoupling is often required. Magnetization transfer can be mediated by a choice of mechanisms: through space via dipolar couplings, or through chemical bonds via $J$-couplings. The progress made in $J$-based sequences, see Refs. [57,64] for instance, has been recently discussed $[1,65,66]$ and will not be considered here in detail. As previously mentioned, in many cases the homonuclear dipolar recoupling schemes must be adapted, as the recoupling sequences that are employed at low MAS are either not efficient anymore at ultra-fast MAS or their RF requirements are too elevated for the current instruments and samples. For example, symmetry-based pulse sequences such as SPC5 [67] or C7 and POST-C7 [68,69] require an irradiation of, respectively, 5 and 7 times the MAS frequency on the low-frequency channel. An important advantage of ultra-fast MAS is that ${ }^{1} \mathrm{H}$ decoupling can be omitted in many recoupling sequences such as DREAM [49], RFDR [70], CMpRR [71], and ${ }^{15} \mathrm{~N}-{ }^{13} \mathrm{C}$ SPECIFIC-CP $[41,60]$. Another important advance in recent years is the emergence and better understanding of second-order recoupling sequences. The present section will highlight the particularities of dipolar recoupling techniques at ultra-fast MAS. We will discuss separately firstorder and second-order recoupling techniques. Here, first-order indicates that the effect occurs due to the first term of the Magnus expansion in the average Hamiltonian treatment of the pulse sequence [72], while second-order effects arise due to the second term (commutator terms) of the Magnus expansion.

\subsection{First-order dipolar recoupling: homonuclear}

First-order dipolar recoupling experiments fall into two categories depending on whether their effective Hamiltonian is of double-quantum (DQ) or zero-quantum (ZQ) nature [73]. The important consequence is that the transferred magnetization will change its sign for DQ transfer but not for ZQ. For DQ mixing, this makes it possible to distinguish between direct transfers, which have negative cross-peaks relative to the diagonal, and relay transfers (i.e. two subsequent transfers during the same mixing period) which have positive cross-peaks.

Because of its low RF requirements, the double-quantum homonuclear rotary-resonance condition, DQ-HORROR [74], is frequently employed (Eq. (5)). In this sequence, $c w$ irradiation is applied on the $\mathrm{X}$ channel at approximately $\frac{1}{2} v_{r}$, such that the sum of effective fields on $\mathrm{A}$ and $\mathrm{B}$ equals the MAS frequency. Here, $\mathrm{X}$ represents the

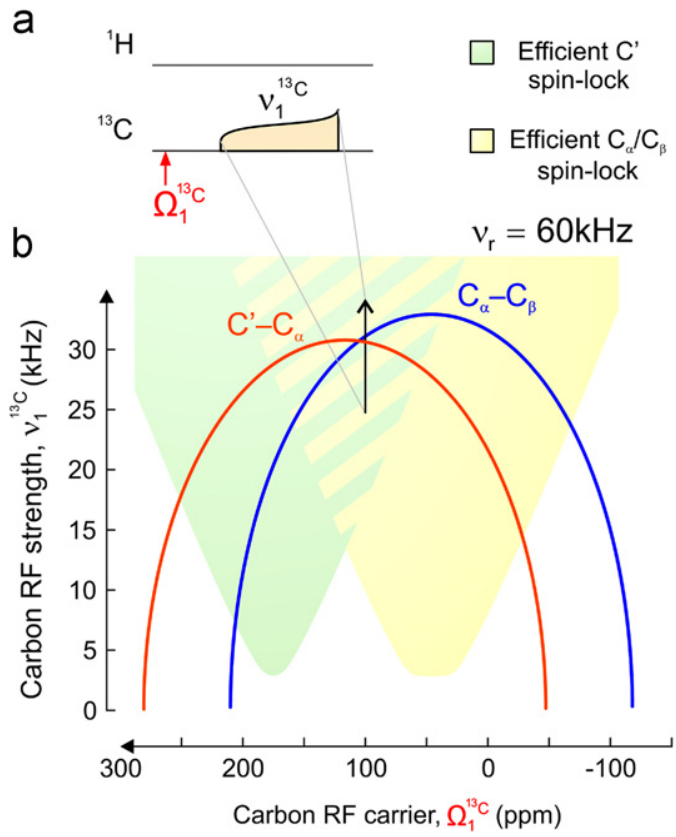

Fig. 4. Optimization of ${ }^{13} \mathrm{C}-{ }^{13} \mathrm{C}$ DREAM transfer. (a) The DREAM recoupling element is characterized by the carrier position $\Omega_{1}^{13} \mathrm{C}$ and the average RF strength $v_{1}^{X}$. At ultra-fast MAS, no ${ }^{1} \mathrm{H}$ decoupling is applied during recoupling. (b) Calculated transfer conditions for $\mathrm{C}^{\prime}-\mathrm{C}_{\alpha}$ transfer (orange) and $\mathrm{C}_{\alpha}-\mathrm{C}_{\beta}$ transfer (blue). Transfer occurs at different RF strengths because of their different chemical shift separation, as calculated from Eq. (5). Typical ${ }^{13} \mathrm{C}$ isotropic chemical shifts are considered: $C^{\prime}(175.8 \mathrm{ppm}), C_{\alpha}(57.5 \mathrm{ppm})$ and $C_{\beta}(34.6 \mathrm{ppm})$. The black arrow represents the amplitude of the RF field during a DREAM adiabatic sweep with carrier position at $100 \mathrm{ppm}$. Recoupling can be achieved off-resonance but the spin-lock is inefficient, leading to magnetization loss. Approximate regions of efficient spin-lock, as observed in ubiquitin at $18.8 \mathrm{~T}$, are highlighted in green for $\mathrm{C}^{\prime}$ and in yellow for $C_{\alpha} / C_{\beta}$. The mixing duration for DREAM is optimized between 2 and $10 \mathrm{~ms}$.

nucleus for which recoupling occurs (e.g. ${ }^{13} \mathrm{C}$ and ${ }^{15} \mathrm{~N}$ ). The recoupling is commonly realized with the adiabatic version of DQ-HORROR, namely the DREAM scheme [36], which was first presented as a DQ filter scheme [75]. The initial magnetization is spin-locked with an applied RF of amplitude far inferior or far superior to the HORROR condition. The RF strength is then gradually changed, effectively 'dragging' the spin-system adiabatically through the recoupling condition (Fig. 4a). This makes the sequence robust against RF mismatch and distribution of dipolar coupling frequencies due to crystallite orientation and isotropic chemical shift distribution.

$v_{r}=\underbrace{\sqrt{v_{1}^{2}+\left(\Omega_{i s o}^{A}\right)^{2}}}_{\text {effective field on spin A }}+\underbrace{\sqrt{v_{1}^{2}+\left(\Omega_{i s o}^{B}\right)^{2}}}_{\text {effective field on spin B }}$

$v_{r}$ is the MAS frequency, $v_{1}$ is the RF nutation frequency, and $\Omega_{i s o}$ is the chemical shift offset relative to carrier.

DREAM is narrow-banded at low MAS and broadband at ultrafast MAS, as it can recouple two spins with an isotropic chemical shift separation of up to $\frac{1}{2} v_{r}$. This feature is nicely illustrated in the work of Ernst et al. [49], where ${ }^{13} \mathrm{C}-{ }^{13} \mathrm{C}$ cross-peaks with increasing chemical shift separation appear as the spinning rate is increased from 30 to $60 \mathrm{kHz}$. This work also demonstrates that above a given spinning rate ( $\geq 50 \mathrm{kHz}$ MAS), cross-peak intensities are unaffected by the presence or absence of ${ }^{1} \mathrm{H}$ decoupling. The RF field strength employed for the DREAM shaped pulse depends on both the carrier position $\Omega_{1}^{X}$ and the chemical shift separation of the recoupled spin pair. Fig. $4 \mathrm{~b}$ illustrates the different RF fields required for $\mathrm{C}_{\alpha}-\mathrm{C}^{\prime}$ and $\mathrm{C}_{\alpha}-\mathrm{C}_{\beta}$, transfers. Practically, the best transfer conditions are obtained with the carrier 
frequency set to the middle of the range of resonances to be recoupled and the average irradiation frequency slightly below $\frac{1}{2} v_{r}$ [36]. Due to the distribution of chemical shifts in proteins, different spin pairs cross the resonance condition at different times during the adiabatic sweep [76]. For example, as seen from the arrow depicted in Fig. $4 \mathrm{~b}$, the $\mathrm{C}^{\prime}-\mathrm{C}_{\alpha}$ condition is traversed before the $C_{\alpha}-C_{\beta}$ condition. This leads to an intricate pattern of magnetization transfer and asymmetric cross-peak intensities in 2D spectra.

New DQ recoupling schemes have also been recently introduced for the study of ${ }^{19} \mathrm{~F}-{ }^{19} \mathrm{~F}$ proximities $[77,78]$ or for ${ }^{31} \mathrm{P}$ recoupling [79]. Symmetry-based techniques are utilized in these schemes in order to be more robust against the broad range of ${ }^{19} \mathrm{~F}$ chemical shifts, or against the large ${ }^{31} \mathrm{P}$ CSA.

The sign alternation is not encountered when using ZQ recoupling, of which the chief sequence at ultra-fast MAS is RFDR. In this sequence, a train of rotor-synchronized $\pi\left(180^{\circ}\right)$ pulses is applied on the $\mathrm{X}$ channel in the middle of every rotor period (Fig. 5b). RFDR has been firstly analyzed considering $\pi$ pulses as delta functions [37,38], where dipolar couplings are restored only in an interaction frame which involves both $\mathrm{RF}$ and isotropic chemical shifts. However, it was then found that when finite pulse-width effects are considered, an interaction frame involving the $\mathrm{RF}$ is sufficient to re-introduce the dipolar coupling, making RFDR largely insensitive to chemical shift offsets [81,82]. RFDR is versatile in the slow and fast MAS regimes $(<40 \mathrm{kHz})$, as it can be used in broadband or band-selective experiments. The band-specific implementation requires weaker-RF $\pi$ pulses which occupy a larger fraction of the rotor period. In a study by Bayro and coworkers [83], this specificity has been combined with sparse labeling in order to reduce the number of actively recoupled nuclei and circumvent dipolar truncation. A large amount of aliphatic correlations, including long-range $\mathrm{C}_{\alpha}-\mathrm{C}_{\alpha}$ contacts, could be obtained at $12.5 \mathrm{kHz}$ MAS in $\left[2-{ }^{13} \mathrm{C}\right]$ glycerol-labeled $\mathrm{PI} 3-\mathrm{SH} 3$ amyloid fibrils. At ultra-fast MAS, RFDR is used as a broadband sequence

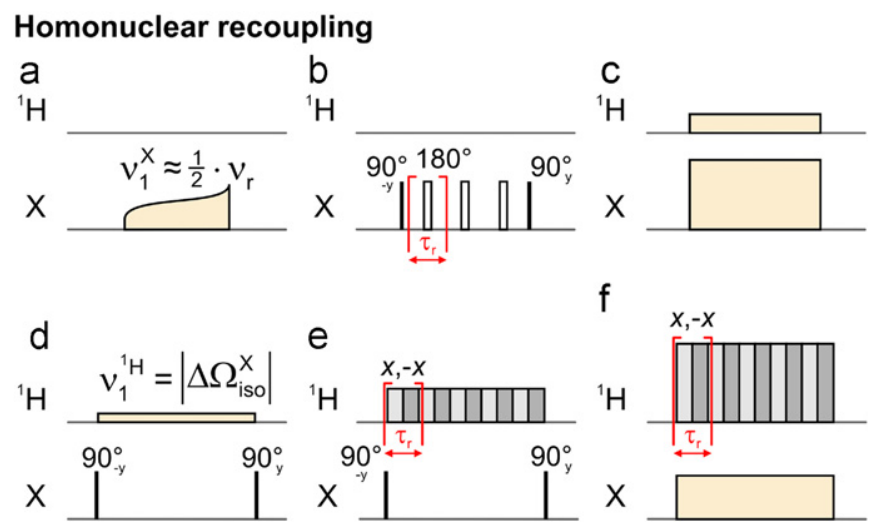

Fig. 5. Building blocks for homonuclear recoupling at ultra-fast MAS. Representation of pulse sequence elements for homonuclear recoupling and spin diffusion at ultra-fast MAS: (a)-(b) first-order sequences and (c)-(f) second-order sequences. Initial magnetization on the $x$-axis of a first X-nuclei spin is transferred to $x$-axis magnetization of a second spin of the same isotope. Continuous-wave irradiation is denoted by yellow pulses and phase-alternated irradiation $(x,-x)$ by light and dark gray blocks. For both channels, the carrier position is set in the mid-range $\Omega_{1}^{X}=\frac{1}{2}\left(\Omega_{\min }^{X}+\Omega_{\max }^{X}\right)$ of frequencies to be recoupled. (a) In DREAM, $v_{1}^{X}$ is the average $\mathrm{RF}$ strength at midpoint during the sweep, as selected from Fig. 4b. Rotorsynchronized pulses are employed for (b) RFDR, (e) PARIS, and (f) RESORT, with the period indicated in red (n.b. $\tau_{r}=v_{r}^{-1}$ ). For RFDR, the pulse is centered during one rotor period and $\tau_{\text {pulse }} \ll \tau_{r}$. For PARIS and RESORT, the duration for each pulse is half the rotor period. (c) For ${ }^{13} \mathrm{C}-{ }^{13} \mathrm{C}$ PAR at $65 \mathrm{kHz}$ MAS, a low-power condition of $\left(v_{1}^{13} \mathrm{C} \approx 1.12 v_{r}, v_{1}^{1} \mathrm{H} \approx 0.3 v_{r}\right)$ can be exploited for biological samples. (d) In MIRROR-SD, $\left|\Delta \Omega_{i s o}^{X}\right|$ refers to the isotropic chemical shift separation between the two low- $\gamma$ nuclei of interest. More information on pulse settings for PAR and RESORT is available in Ref. [45,80,32], respectively. (For interpretation of the references to color in this figure legend, the reader is referred to the web version of this article.) and ${ }^{1} \mathrm{H}$ decoupling is generally omitted [62]. Proton irradiation can reintroduce depolarization conditions which are only avoided through a careful selection of ${ }^{1} \mathrm{H}$ RF strength, with independent levels chosen for the duration of the $\pi$ pulse and for the window between pulses [70] Proper phase cycling of the $\pi$ pulses is critical to eliminate residual DQ dipolar terms or chemical shift terms. Usually, supercycles of the $\mathrm{XY}-4$ scheme $(X Y-8, X Y-16, X Y-32)$ are employed [81-83]. These phase cycling schemes are beneficial in attenuating the imperfections introduced by the large number of consecutive $\pi$ pulses.

\subsection{First-order dipolar recoupling: heteronuclear}

For sensitivity reasons, the initial polarization in ssNMR experiments originates from protons. It is then transferred to low- $\gamma$ nuclei (e.g. ${ }^{13} \mathrm{C}$ or ${ }^{15} \mathrm{~N}$ ). Hartmann-Hahn cross-polarization (CP) is the most common technique for this transfer [84,85]. The ZQ and DQ recoupling conditions used in Hartmann-Hahn CP are described in Fig. 7a. The use of an adiabatic ramp is recommended to increase transfer efficiency [86-88], for reasons similar to those previously exposed for the DREAM scheme. While the RF strengths employed must be sufficiently strong to spin-lock the desired chemical shift ranges, a special attention must be paid to minimize the power deposition. The DQ $n=1$ condition constitutes the first-order recoupling condition with the lowest RF requirements. In a work by Laage et al. [89], this condition is used in a band-selective fashion in order to excite either the carbonyl or the aliphatic ${ }^{13} \mathrm{C}$ region of human SOD. RF field strengths of $v_{1}^{13} \mathrm{C}=14 \mathrm{kHz}, v_{1}^{1} \mathrm{H}=46 \mathrm{kHz}$ are employed at $60 \mathrm{kHz}$ MAS, as illustrated in Fig. $6 a$.

Hartmann-Hahn transfers between ${ }^{15} \mathrm{~N}$ and ${ }^{13} \mathrm{C}$ are an important component of $\mathrm{N}-\mathrm{C}, \mathrm{N}-\mathrm{C}-\mathrm{C}$, and $\mathrm{C}-\mathrm{N}-\mathrm{C}$ correlation experiments, sometimes referred to as double cross-polarization (DCP) experiments. Band-specific transfers are employed similarly to the SPECIFIC-CP technique introduced by Baldus and coworkers $[91,92]$. As any ZQ condition would require strong irradiation on at least one of the low-frequency channels, the DQ $n=1$ condition

\section{${ }^{1} \mathrm{H}-\mathrm{X}$ recoupling}

$$
\begin{aligned}
& \text { a } \quad \text { b } \quad \text { c }
\end{aligned}
$$

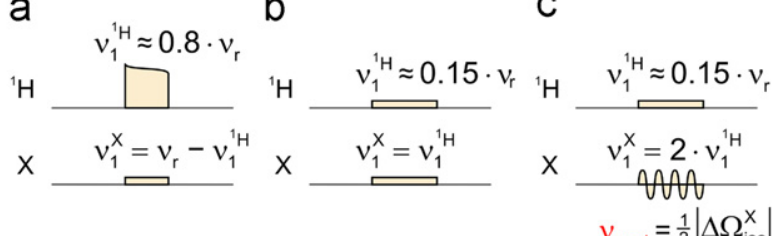

${ }^{15} \mathrm{~N}-{ }^{13} \mathrm{C}$ recoupling

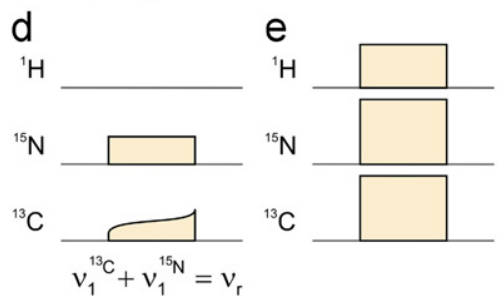

Fig. 6. Building blocks for heteronuclear recoupling at ultra-fast MAS. Pulse sequence elements for ${ }^{1} \mathrm{H}-\mathrm{X}$ and ${ }^{15} \mathrm{~N}-{ }^{13} \mathrm{C}$ transfers. The initial state of the spinsystem are (a)-(c) $\hat{I}_{x}^{\mathrm{H}}$, and (d)-(e) $\hat{S}_{x}{ }^{\mathrm{N}}$; the desired final states are (a)-(c) $\hat{S}_{x}^{X}$, and (d)-(e) $\hat{S}_{x} \mathrm{C}$. For all channels, the carrier position is set to the mid-range of frequencies to be recoupled. RF field strength recommendations are indicated for (a)-(d), see also Fig. 7b and c. For MOD-CP, a cosine amplitude modulation of frequency $v_{\text {mod }}$ is applied on the $\mathrm{X}$ channel. Adiabatic amplitude sweeps are applied for ${ }^{1} \mathrm{H}-\mathrm{X}$ band-specific $\mathrm{CP}$ and ${ }^{15} \mathrm{~N}-{ }^{13} \mathrm{C}$ SPECIFIC-CP. (e) Pulse settings and durations for PAIN-CP are discussed in Ref. [90]. 
(Eq. (6)) is the condition of choice at ultra-fast MAS (Fig. 6d).

$v_{1}^{13} \mathrm{C}+v_{1}^{15} \mathrm{~N}=v_{r}$

An adiabatic amplitude sweep is commonly employed on ${ }^{13} \mathrm{C}$ to increase the long-term stability of the experiment [24]. The RF fields on both channels must be chosen so as to prevent homonuclear recoupling conditions such as HORROR $\left(v_{R F}=\frac{1}{2} v_{r}\right)$, or rotary resonance $\left(v_{R F}=v_{r}\right)$. As ${ }^{13} \mathrm{C}$ has a large chemical shift range, RF frequencies between $\frac{1}{3} v_{r}$ and $\frac{2}{3} v_{r}$ should be avoided, especially at high fields or with a large adiabatic sweep. Alternatively, the adiabatic amplitude sweep can be done on the ${ }^{15} \mathrm{~N}$ channel. Efficient transfers have been accomplished without proton decoupling at $40 \mathrm{kHz}$ MAS and above [41,60]. Strong ${ }^{1} \mathrm{H}$ decoupling $\left(v_{1}{ }^{1} \approx 2.5 v_{r}\right)$ is required in the fast MAS regime $(20 \mathrm{kHz})[90,93]$, although efficient transfers might be possible in some conditions in the absence of ${ }^{1} \mathrm{H}$ decoupling [94].

\subsection{Second-order recoupling}

The previously mentioned first-order recoupling sequences are necessarily susceptible to the phenomenon of dipolar truncation [40,95]: in a multi-spin system, magnetization is preferentially transferred to a strongly coupled partner, extinguishing transfer to a weakly coupled partner. Sequences operating through a second-order mechanism, less prone to dipolar truncation, are appropriate for transfer to remote nuclei and collection of longrange distance restraints. Second-order recoupling sequences that work well in the ultra-fast MAS regime include PAR $[45,80,96]$, MIRROR-SD [31], RESORT [32], and PARIS [33,34,97] in the homonuclear case; PAIN-CP [90,93], SOCP [98], MOD-CP [44], and MIRROR-CP [99] in the heteronuclear case.

The general designation of third spin assisted recoupling (TSAR) describes a mechanism $\mathrm{B}-[\mathrm{A}]-\mathrm{C}$ where two nuclei $\mathrm{B}$ and $C$ are recoupled through their respective dipolar coupling with a third spin A (i.e. B-A and C-A couplings) rather than directly $[93,96,100]$. The first use of the TSAR mechanism for magnetization transfer has been introduced in a work by Lewandowski and coworkers with Proton assisted insensitive nuclei cross-polarization (PAIN-CP) where second-order $\mathrm{N}-\mathrm{C}$ transfer was demonstrated at $20 \mathrm{kHz}$ MAS [93]. The ${ }^{15} \mathrm{~N}-\left[{ }^{1} \mathrm{H}\right]-{ }^{13} \mathrm{C}$ TSAR mechanism is obtained by applying $\mathrm{CW}$ irradiation simultaneously on three channels (Fig. 6e): ${ }^{1} \mathrm{H},{ }^{13} \mathrm{C}$, and ${ }^{15} \mathrm{~N}$. A thorough theoretical description of PAIN was recently published [90]. The homonuclear analog of PAIN, Proton assisted recoupling (PAR), generates $\mathrm{X}-\left[{ }^{1} \mathrm{H}\right]-\mathrm{X}$ transfer by concurrent $c w$ irradiation on the proton and $X$ channel (Fig. 5c). For ${ }^{15} \mathrm{~N}-{ }^{15} \mathrm{~N}$ PAR at $20 \mathrm{kHz}$ MAS $\left(v_{1}{ }^{1}=v_{1}{ }^{15} \mathrm{~N}>2 v_{r}\right)$ and $\left(v_{1}{ }^{15} \approx 0.2 v_{r}, v_{1}{ }^{1} \mathrm{H} \approx 3 v_{r}\right)$ are suggested. Inter-nuclear proximities can be probed from the build-up of transferred intensity during the PAR element, as demonstrated with ${ }^{13} \mathrm{C}-{ }^{13} \mathrm{C}$ cross-peak build-ups in microcrystalline Crh [96]. The use of PAR at ultra-fast MAS (65 kHz MAS) was demonstrated on microcrystalline GB1 [45] where ${ }^{13} \mathrm{C}-{ }^{13} \mathrm{C}$ correlations could be obtained with a low-power condition of $\left(v_{1}^{13} \mathrm{C} \approx 1.12 v_{r}\right.$, $\left.v_{1}{ }^{1} \mathrm{H} \approx 0.3 v_{r}\right)$. A condition at $\left(v_{1}^{13} \mathrm{C} \approx 1.75 v_{r}, v_{1}{ }^{1} \mathrm{H} \approx 1.3 v_{r}\right)$ has also been used. Possible optimization protocols for PAR are discussed in Refs. $[45,80]$. When setting up a PAR or a PAIN experiment, an important aspect is to avoid RF frequencies which lead to firstorder recoupling conditions (e.g. HORROR, rotary resonance, and Hartmann-Hahn matching). First, the regions to be excluded from the optimization space are identified by simulating an interference map of the spin system. RF power levels are then optimized around regions of known high transfer, identified from a polarization transfer map. Scripts for generating such maps, including $\mathrm{C}_{\alpha}-\mathrm{C}_{\beta}, \mathrm{C}_{\alpha}-\mathrm{C}^{\prime}$, and $\mathrm{C}_{\alpha}-\mathrm{C}_{\gamma}$ transfers, are available [45].
Analogous to PAR, the RESORT experiment has been presented for homonuclear transfer [32]. The low- $\gamma$ nuclei are spin-locked with $c w$ irradiation; however in this case, phase-alternated irradiation is applied on ${ }^{1} \mathrm{H}$ (Fig. 5f). This generates an effective Hamiltonian with the same form as for PAR but with different transfer conditions. RESORT has been demonstrated at $40 \mathrm{kHz}$ MAS on microcrystalline ubiquitin.

In contrast to previous sequences, second-order recoupling can also be accomplished with sequences where no irradiation is applied on the $\mathrm{X}$ channel. For example, proton spin diffusion $\left({ }^{1} \mathrm{H}-{ }^{1} \mathrm{H}\right)$ and proton-driven spin diffusion $\left({ }^{13} \mathrm{C}-{ }^{13} \mathrm{C}\right.$ or $\left.{ }^{15} \mathrm{~N}-{ }^{15} \mathrm{~N}\right)$ do not require any irradiation during mixing. However, as PDSD relies on energy-level broadening due to homonuclear ${ }^{1} \mathrm{H}-{ }^{1} \mathrm{H}$ and heteronuclear ${ }^{1} \mathrm{H}-\mathrm{X}$ dipolar interactions to increase the spectral overlap between low- $\gamma$ spin pairs, it only functions at low MAS. In the fast MAS range, the dipolar-assisted rotational resonance (DARR) method is used to accelerate the transfer [29,101]. According to Takegoshi and coworkers [101], the effect of irradiating the protons at the rotary-resonance condition (Eq. (7)) is to restore the spectral overlap between a sideband of an $X$ spin and the ${ }^{1} \mathrm{H}-\mathrm{X}$ dipolar pattern of another $\mathrm{X}$ spin. Spin-diffusion mediated by DARR is abolished at ultra-fast MAS. Indeed, in a study by Scholz and coworkers, it was found that irradiating at the $n=1$ or $n=2$ DARR condition could not induce $C^{\prime}$ to $C_{\alpha}$ transfer at $45 \mathrm{kHz}$ MAS [31]. Instead, proton irradiation at the mixed rotational and rotary-resonance (MIRROR) condition was found to mediate spin-diffusion (Fig. 5d). The strongest transfer occurs when the applied field on ${ }^{1} \mathrm{H}$ matches the ${ }^{13} \mathrm{C}$ chemical shift difference (Eq. (8), $n=0$ ). The recoupling can be carried out using phase-alternated irradiation instead of $c w$, providing increased robustness against $v_{1}^{1}$ mismatch. Because of the dependence on ${ }^{13} \mathrm{C}$ chemical shift, MIRROR is an intrinsically band-selective sequence. This building block is particular in that it has a dual function and can promote both ${ }^{13} \mathrm{C}-{ }^{13} \mathrm{C}$ recoupling (MIRROR-SD) and ${ }^{1} \mathrm{H}-{ }^{13} \mathrm{C}$ transfer (MIRROR-CP) [99]. The PARIS scheme has also been proposed to promote ${ }^{13} \mathrm{C}-{ }^{13} \mathrm{C}$ recoupling [33] and it employs phase-alternated ${ }^{1} \mathrm{H}$ pulses which have a duration of either $\frac{1}{2}$ or 2 times the rotor period (Fig. 5e). PARIS- $x y$, a variant of PARIS with the $x,-x,-y, y$ phase cycle [34], was recently used in the $39-52 \mathrm{kHz}$ MAS range to record ${ }^{13} \mathrm{C}-{ }^{13} \mathrm{C}$ correlations in selectively labeled amyloid- $\beta$ peptides [97].

$v_{1}^{1} \mathrm{H}=n v_{r}, \quad n=\{1,2\}$

$v_{1}^{1}{ }^{1 \mathrm{H}}=n v_{r} \pm \Delta \Omega_{\text {iso }}^{13} \mathrm{C}, \quad n=\{0, \pm 1, \pm 2, \pm 3, \pm 4\}$

Second-order processes can also accomplish the initial crosspolarization from ${ }^{1} \mathrm{H}$ to low- $\gamma$ nuclei. Indeed, second-order cross-polarization (SOCP) was introduced in a study by Lange et al. [98]. An important observation is that decay during ${ }^{1} \mathrm{H}$ spinlock is highly dependent on the applied RF strength. Efficient spin-locking of ${ }^{1} \mathrm{H}$ magnetization does not require strong $\mathrm{RF}$ fields, but can be accomplished with low-power irradiation, e.g. $9.4 \mathrm{kHz}$ at $65 \mathrm{kHz}$ MAS. The most efficient ${ }^{1} \mathrm{H}$ RF frequencies only appear at certain ratios of the MAS frequency, usually with $v_{1}{ }_{1} \mathrm{H}$ equal to $0.15,1.67$, and 2.55 times $v_{r}$ (Fig. 7c). Those ratios are identified by monitoring the signal intensity as a function of ${ }^{1} \mathrm{H}$ spin-lock field. SOCP is achieved with the $n=0$ Hartman-Hahn condition: $v_{1}^{1}=v_{1}^{\mathrm{X}}$ (Fig. 6b). The predominant transfer mechanism is due to second-order cross-terms between homonuclear and heteronuclear dipolar couplings, although transfer can in principle also occur through J-couplings. Notable advantages of SOCP are the higher sensitivity compared to first-order highpower $\mathrm{CP}$, as initial magnetization can originate from protons not directly coupled to the $S$ spin, and the robustness against RF field inhomogeneities, due to matching at the $n=0$ condition. SOCP is 


$$
\begin{aligned}
& \text { a } \quad \text { ZQ } v_{1}^{1}{ }^{1 H}-v_{1}^{x}=n \cdot v_{1}^{1}, \quad n=\{-2,-1,+1,+2, \ldots\} \\
& { }^{13} \mathrm{C} \quad v_{1}^{13 \mathrm{C}} \mathrm{DQ} v_{1}^{1 \mathrm{H}}+v_{1}^{\mathrm{X}}=\mathrm{n} \cdot v_{\mathrm{r}}, \mathrm{n}=\{1,2, \ldots\}
\end{aligned}
$$

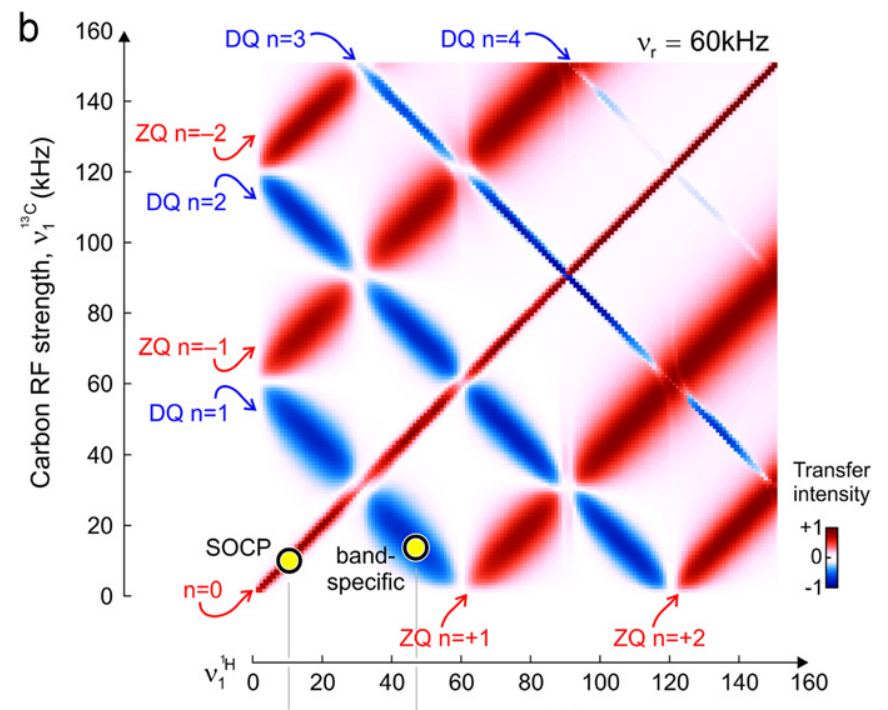

C

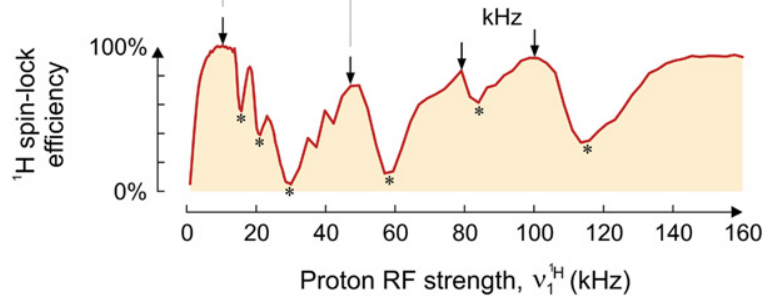

Fig. 7. Selecting optimal ${ }^{1} \mathrm{H}-\mathrm{X}$ cross-polarization conditions at ultra-fast MAS. (a) Pulse scheme for ${ }^{1} \mathrm{H}-{ }^{13} \mathrm{C} \mathrm{CP}$. The ZQ (red) and DQ (blue) Hartmann-Hahn conditions lead, respectively, to positive and negative transfers. (b) Map of magnetization transfer at $60 \mathrm{kHz}$ MAS simulated for a $\mathrm{CH}_{2}$ group, considering the ${ }^{1} \mathrm{H}-{ }^{1} \mathrm{H}$ and ${ }^{1} \mathrm{H}-{ }^{13} \mathrm{C}$ dipolar couplings. In addition to $n= \pm 1, \pm 2 \mathrm{ZQ}$ and $n=1,2$ DQ conditions, transfer conditions due to higher order terms appear: the $n=0$ condition used in SOCP, as well as the $n=3$ and $n=4$ DQ conditions. The RF settings for SOCP and band-specific $\mathrm{CP}$ are indicated. Intensities correspond to the average ${ }^{13} \mathrm{C}$ magnetization for time points between 6 and $8 \mathrm{~ms}$. (c) Efficiency of ${ }^{1} \mathrm{H}$ spin-lock as a function of RF strength, as measured after $2.5 \mathrm{~ms}$ of spin-lock in $\left[{ }^{15} \mathrm{~N},{ }^{13} \mathrm{C}\right]$-labeled glutamine. Conditions of least decay, indicated by arrows, should be employed for CP. Deleterious recoupling conditions at ratio of $\frac{1}{4}, \frac{1}{3}, \frac{1}{2}, 1, \frac{3}{2}$, and 2 times $v_{r}$ are indicated by asterisks.

Part (c) is adapted from Ref. [44].

employed in a band-selective fashion in the construction of a complete set of experiments for protein assignment at ultra-fast MAS (Fig. 2). For the initial H-X transfer, a limited bandwidth is adequate for $\mathrm{N}-\mathrm{C}$ experiments; however, broadband excitation may be desired in the case of $\mathrm{C}-\mathrm{C}$ spectra. The RF strength on both channels can then be slightly increased to $19 \mathrm{kHz}$ at $60 \mathrm{kHz}$ MAS, therefore avoiding the higher order $v_{1}=\frac{1}{4} v_{r}$ and $v_{1}=\frac{1}{3} v_{r}$ recoupling conditions. When two regions present a large chemical shift separation $\left|\Delta \Omega_{i s o}^{X}\right|$, for instance $C^{\prime}$ and $C_{\alpha}$ in proteins, the simultaneous excitation of both regions is achievable at low-power through the amplitude-modulated second-order cross-polarization scheme (MOD-CP) [44]. In the MOD-CP scheme, a cosine amplitude modulation with frequency $v_{\text {mod }}=\frac{1}{2}\left|\Delta \Omega_{\text {iso }}^{X}\right|$ is applied on the $\mathrm{X}$ channel (Fig. 6c). The ${ }^{13} \mathrm{C}$ RF strength is doubled, $v_{1}^{X}=2 v_{1}{ }_{1} \mathrm{H}$, creating the two distinct excitation regions. The simultaneous excitation of $\mathrm{C}^{\prime}$ and $\mathrm{C}_{\alpha}$, or $\mathrm{C}^{\prime}$ and $\mathrm{C}_{\beta}$ regions is demonstrated in microcrystalline ubiquitin at $60 \mathrm{kHz}$. MOD-CP restores the high information content per spectrum as found in highpower broadband excitation, while limiting the RF expenditure of the pulse sequence. MOD-CP can potentially be exploited for the study of organic materials, since several other spin-1/2 nuclei such as ${ }^{31} \mathrm{P},{ }^{15} \mathrm{~N},{ }^{29} \mathrm{Si}$, and ${ }^{19} \mathrm{~F}$ cover a large range of isotropic chemical shifts.

\section{Proton NMR at ultra-fast MAS}

So far in ssNMR, mostly rare low- $\gamma$ nuclei such as ${ }^{13} \mathrm{C}$ and ${ }^{15} \mathrm{~N}$ have been employed for detection, for observation in indirect dimensions, and for obtaining distance restraints. On the other hand, protons have the advantage of a high gyro-magnetic ratio $\gamma$, an almost $100 \%$ natural abundance, and a molar content of more than $50 \%$ in biomolecules and in numerous other systems of interest. As sensitivity at detection is proportional to $\gamma^{3 / 2}$, at the same line-width, detection via ${ }^{1} \mathrm{H}$ would be, respectively, 8 and 31 times more sensitive than detection via ${ }^{13} \mathrm{C}$ and ${ }^{15} \mathrm{~N}$. In general, sensitivity gains via proton detection in 2D HETCOR experiments depend as well on line-width and quality factor of the probe coils, as it has been described by Ishii and Tycko [102].

Inter-nuclear proximities in solid-state NMR are estimated from dipole-dipole couplings, which are proportional to the product of gyro-magnetic ratios $\gamma_{1}$ and $\gamma_{2}$ of both nuclei involved in the interaction. As a consequence of ultra-fast MAS, ${ }^{13} \mathrm{C}-{ }^{13} \mathrm{C}$ and ${ }^{15} \mathrm{~N}-{ }^{15} \mathrm{~N}$ spin diffusion is significantly reduced $[53,103,104]$ and cannot be efficiently used for the collection of distance restraints. For the same inter-nuclear distance, ${ }^{1} \mathrm{H}-{ }^{1} \mathrm{H}$ dipolar couplings are 16 and 97 times stronger than ${ }^{13} \mathrm{C}-{ }^{13} \mathrm{C}$ and ${ }^{15} \mathrm{~N}-{ }^{15} \mathrm{~N}$ couplings, respectively. This would potentially allow to obtain long-range distance restraints based on ${ }^{1} \mathrm{H}-{ }^{1} \mathrm{H}$ magnetization transfer $[46,47,105]$. Another benefit of proton observation is resolution enhancement by the introduction of additional proton dimension(s), which can simplify the process of resonance assignment.

However, the major limitation for ${ }^{1} \mathrm{H}$ observation in ssNMR relates directly to its high natural abundance, high density, and high gyro-magnetic ratio: networks of strong proton-proton dipolar couplings result in very broad lines of ca. $50 \mathrm{kHz}$ for static samples. In the high-field approximation, the spin Hamiltonian of the homonuclear dipolar coupling of spins $S$ and $K$ is given by Eq. (9). The instantaneous dipolar coupling $d(\theta(t))$ depends on the orientation of the inter-nuclear vector with respect to the external magnetic field, given by the Euler angle $\theta$ (Eq. (10)). The angle $\theta$ is time-modulated due to MAS. The maximum value of $d(\theta(t))$ for two protons at a distance of $2.5 \AA$ is $7.8 \mathrm{kHz}$.

$H_{D}=d(\theta(t))\left[2 S_{z} K_{z}-S_{x} K_{x}-S_{y} K_{y}\right]$

$S_{x, y, z}$ are the Cartesian components of spin operators $S$ and $K$.

$d(\theta(t))=\frac{\mu_{0}}{4 \pi} \frac{\gamma^{2} \hbar}{r^{3}} \frac{1-3 \cos ^{2}(\theta(t))}{2}$

$r$ is the inter-nuclear distance, $\gamma$ is the gyro-magnetic ratio, $\hbar$ is the reduced Planck constant.

There are now three major approaches to increase proton resolution [6]: (1) proton dilution with deuterium [106], (2) proton-proton radio-frequency homonuclear decoupling [107], and (3) magic-angle spinning at rates ( $>30 \mathrm{kHz}$ MAS) that are comparable with homonuclear dipolar interactions [108]. Additionally, a combination of these techniques is commonly exploited. The first approach provides the best ${ }^{1} \mathrm{H}$ line narrowing so far, with line-widths on the order of $20 \mathrm{~Hz}$ in microcrystalline SH3 [109] at MAS rates below $20 \mathrm{kHz}$. However, the use deuteration can require adopting or establishing new sample preparation protocols. Radio-frequency ${ }^{1} \mathrm{H}-{ }^{1} \mathrm{H}$ decoupling is efficient in combination with MAS, which removes other anisotropic interactions such as CSA and heteronuclear dipolar couplings as well. Numerous experimental techniques were developed in this field since the 
early days of NMR and resulted in achievable line-widths on the order of $150-200 \mathrm{~Hz}$ in dry model compounds [110]. A major advantage of this concept is the possibility of routine experimental implementation without the need for special ssNMR instrumentation (i.e. ultra-fast MAS probe-head) and on samples with natural hydrogen abundance. In the third approach of using only mechanical spinning of the sample for suppression of strong homonuclear couplings, it was possible to observe resolved proton resonances in model compounds at the relatively slow spinning rate of $15 \mathrm{kHz}$ [111]. Recently, ultra-fast commercial MAS probe-heads have become available with reachable spinning rates up to $80 \mathrm{kHz}$ (JEOL, Japan) [5]. Certainly, these rates are not sufficient to suppress proton-proton dipolar interactions to an insignificant level, but they still provide remarkably good averaging of protonproton homonuclear dipolar couplings and yield high-resolution proton spectra (Fig. 8). Remarkably, the spinning frequencies in ultra-fast MAS are getting very close to effective RF field frequencies which are commonly applied for homonuclear proton decoupling in experiments on proteins $[112,113]$. Therefore, one may expect improved decoupling efficiencies of the MAS-alone approach in the near future. Advantages of using ultra-fast MAS alone are simplicity of pulse technique implementation, artifactfree spectra, absence of an isotropic chemical shift scaling factor, and higher sensitivity because of the absence of RF irradiation during acquisition. As well, prevention of sample heating due to RF irradiation is a necessity for short repetition delay experiments and is one of the major advantages of the ultra-fast MAS approach [60] (see also Sections 1 and 3 on Paramagnetic doping and paramagnetic proteins).

For three and more like spins which are interacting through dipolar couplings and are arbitrarily positioned in space, the spin Hamiltonian derived with the help of the Eq. (9) is, in general, not self-commuting at different time points $\left[H\left(t^{\prime}\right), H\left(t^{\prime \prime}\right)\right] \neq 0$ and has therefore a "homogeneous" nature according to the classification introduced by Maricq and Waugh [114]. As a consequence, proton line-widths are broad even at spinning frequencies exceeding the sum over all proton-proton interactions, and decrease slowly at increasing spinning rates. Maricq and Waugh derived in their pioneering work that the line-width of homonuclear spin systems is inversely proportional to the spinning rate $v_{r}$. Later, the proton line-shape dependence on sample spinning has been theoretically discussed by a number of other authors $[73,108,115,116]$. Levitt et al. [73] found that at some geometrical configurations of proton systems the line-widths can be proportional to $\left(\Delta \delta v_{r}^{2}\right)^{-1}$, where $\Delta \delta$ is the chemical shift difference of two spins. Using Floquet theory together with standard perturbation theory and numerical

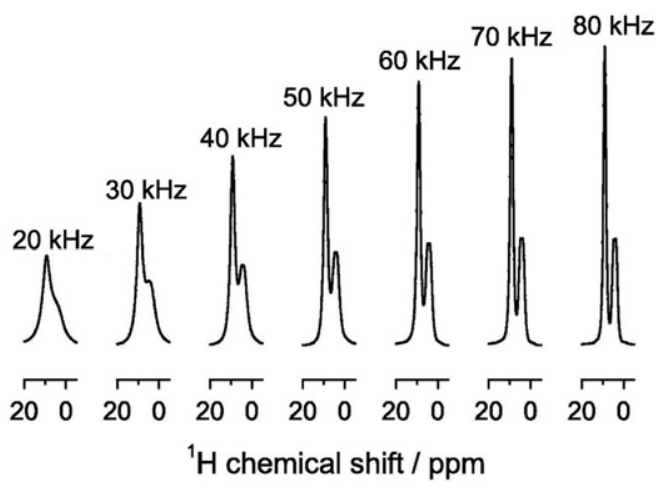

Fig. 8. Single pulse ${ }^{1} \mathrm{H}$ spectra of glycine at various spinning frequencies. This figure illustrates the impact of ultra-fast spinning on proton resolution and sensitivity. The undecoupled, proton-detected glycine spectra were obtained in the range of spinning rates between $20 \mathrm{kHz}$ and $80 \mathrm{kHz}$ in studies of Nishiyama and coworkers [5]. simulations, Ray and coworkers [115] found different power dependences of the proton line-width on $v_{r}$, falling in a range between -1.1 and -2 depending on local spin density and mutual proton orientation. Still, the comprehensive theoretical and even numerical treatment of homonuclear multi-spin systems under MAS remains a formidable challenge.

Previously, extensive experimental studies of proton linewidth in different systems had been performed by a number of research groups in the fast spinning regime $(20-40 \mathrm{kHz})$, limited by the technologically allowed spinning rate at that time [102,116,119-121]. They could confirm the prediction that the line-width is approximately inversely proportional to the spinning rate and strongly dependent on the local proton density, as well as on other sources of broadening like anisotropic magnetic susceptibility [119,121] and crystallite orientation [118,122]. These studies demonstrate the possibility of sufficient ${ }^{1} \mathrm{H}$ resolution in sSNMR, and are one of the driving forces to increase spinning rates up to $80 \mathrm{kHz}$. Nowadays, many proton-detected experiments are performed in the fast and ultra-fast MAS regime: the rapid characterization of small compounds [123,124], linewidth measurements at different external magnetic fields and MAS rates, and studies on the influence of anisotropic magnetic susceptibility [119] and crystallite orientation [118] on line broadening.

A number of pulse schemes for proton-detected heteronuclear 2D correlation experiments have been designed and can be easily extended to 3D or 4D $[46,47,105]$. Magnetization transfer in HSQC experiments can be performed through CP (Fig. 9a) [125], INEPT (Fig. 9b) [117], or refocused INEPT (Fig. 9c) [46,118]. An HMQCtype experiment $[5,117]$ is shown in Fig. 9d. Zhou and coworkers demonstrated the efficiency of indirect proton detection in 2D HETCOR experiments recorded on fully protonated, uniformly $\left[{ }^{13} \mathrm{C},{ }^{15} \mathrm{~N}\right]$-labeled $\mathrm{GB} 1$ at an MAS rate of $40 \mathrm{kHz}$ [126]. On a spectrometer operating at $500 \mathrm{MHz}$ proton Larmor frequency $(11.75 \mathrm{~T}),{ }^{1} \mathrm{H}$ detection was more sensitive by a factor of 3 and 4 compared with ${ }^{13} \mathrm{C}$ and ${ }^{15} \mathrm{~N}$ detection, respectively. With an instrument operating at $750 \mathrm{MHz}{ }^{1} \mathrm{H}$ Larmor frequency $(17.62 \mathrm{~T}$ ), the sensitivity of proton-detected experiments was 14 times higher compared with ${ }^{15} \mathrm{~N}$-detected heteronuclear correlation experiments, which can be attributed to narrower proton linewidths and improved probe design. Indeed, the average proton line-width of $500 \pm 150 \mathrm{~Hz}$ observed on the $500 \mathrm{MHz}$ spectrometer decreased down to $360 \pm 115 \mathrm{~Hz}$ in experiments performed on the $750 \mathrm{MHz}$ spectrometer. The last effect has been attributed to truncation of homonuclear coupling networks due to the larger isotropic chemical shift dispersion. So far, significant truncation effects have not been observed by other studies on numerous model compounds $[119,121]$ but instead were found for systems which have atypically large chemical shift dispersion and/or very weak dipolar couplings [127], such as systems containing unpaired electrons $[63,128,129]$. Proton line-widths were further reduced by using deuteration. Combined with the advantages of using proton detection and collecting proton-proton distance restraints, this allowed the determination of the 3D structure of microcrystalline GB1 [105]. The protein was uniformly ${ }^{13} \mathrm{C}$ and ${ }^{15} \mathrm{~N}$ labeled, and protonated only on labile sites, resulting in proton line-widths of $140 \pm 30 \mathrm{~Hz}$ on average. Spectra were measured at $39 \mathrm{kHz}$ MAS on a spectrometer operating at $750 \mathrm{MHz}$ proton frequency.

As well, proton line-widths can be modulated by internal motions via two concurrent effects: (1) line narrowing, due to the partial averaging of anisotropic interactions (e.g. dipolar couplings and CSA) [130], and (2) line broadening, due to chemical exchange and transverse relaxation [131,132]. In both cases, the magnitude of the effect depends on the amplitude of motion and will occur only if the motion is not completely 


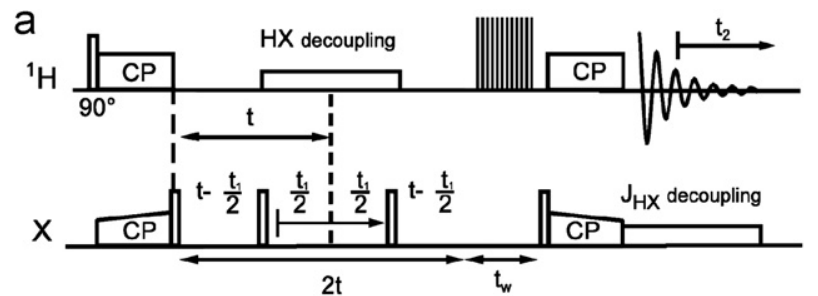

b

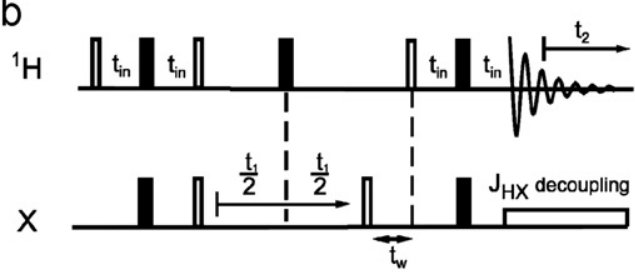

C

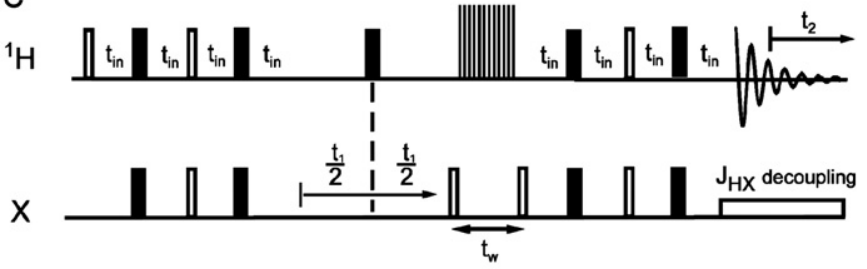

d

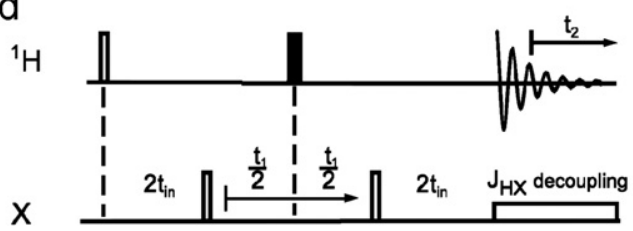

Fig. 9. Indirect proton-detected 2D HETCOR pulse schemes. HSQC experiment based on (a) CP transfer, (b) INEPT, and (c) refocused INEPT. (d) Pulse scheme to obtain HMQC correlations. Conventional notations are used. $\mathrm{X}$ refers to ${ }^{13} \mathrm{C}$ or ${ }^{15} \mathrm{~N}$ nuclei. Evolution periods are represented by $t_{1}$ and $t_{2}$. Open and black bars denote $90^{\circ}$ and $180^{\circ}$ pulses, respectively. Duration for water signal suppression is given by $t_{w}$, where blocks of lines represent saturation pulses. INEPT transfer times $t_{i n}$ in relaxation-free systems are defined by the HX J-coupling as $t_{i n}=\left(4 J_{\mathrm{HX}}\right)^{-1}$. Pulse schemes adapted from Refs. [117,118].

restricted (i.e. with an order parameter $S<1$ ). To observe line narrowing, the frequency of motion $\tau_{c}^{-1}$ must be larger than the anisotropy of the NMR interaction. On the other hand, motions which have the same or slower frequency as the ${ }^{1} \mathrm{H}$ Larmor frequency will lead to relaxation line broadening. In the case of chemical exchange, motions which have a frequency on the same order of magnitude as the difference in proton chemical shift between sites will lead to exchange broadening. Thus, very fast motions $\left(\tau_{c}{ }^{-1} \gg v_{0}{ }^{1} \mathrm{H}\right)$ can facilitate the suppression of ${ }^{1} \mathrm{H}-{ }^{1} \mathrm{H}$ homonuclear couplings by ultra-fast MAS, as they induce line narrowing but not line broadening. Studies on the local dynamics of SH3 domain and ubiquitin [133,134], as well as a number of highly resolved proton spectra for those proteins $[46,109]$, indicated that most residues do not present slow motions of large amplitude, which would lead to significant proton line broadening.

The high sensitivity and resolution approach of using MAS alone was used in the study of model compounds. Zhou and coworkers introduced protocols for rapid analysis of small unlabeled organic compounds [123]. Salager and coworkers [135] reported ${ }^{1} \mathrm{H}$ line-widths between $205 \mathrm{~Hz}$ and $560 \mathrm{~Hz}$ for the model compound $\beta$-L-Asp-L-Ala studied at spinning rates of $65 \mathrm{kHz}$ on a $500 \mathrm{MHz}$ spectrometer. Studies from Holland et al. [118] corroborate the utility of proton detection for the characterization of small molecules like L-alanine, L-isoleucine, and black widow dragline silk.

Additionally, indirect ${ }^{1} \mathrm{H}$ detection offers good opportunities for NMR of ${ }^{14} \mathrm{~N}$, which has high natural abundance and importance in biomolecules and a number of materials, while very poorly suitable for direct detection due to its spin number $I=1$ and related to its quadrupolar interaction. Spinning frequencies up to $80 \mathrm{kHz}$ were used in experiments of Nishiyama et al. resulting in proton-detected ${ }^{14} \mathrm{~N}-{ }^{1} \mathrm{H} 2 \mathrm{D}$ spectra of glycine and glycyl-L-alanine with high sensitivity and resolution [5].

Recent progress has been made in studies of ${ }^{1} \mathrm{H}$ homonuclear decoupling through RF irradiation at ultra-fast MAS. It has been shown that a number of proton-proton decoupling pulse sequences can be successfully applied at MAS rates of $60-65 \mathrm{kHz}$ [136-140] by using RF strengths on the order of $200 \mathrm{kHz}$. The widely used family of PMLG [141,142] and DUMBO [143] homonuclear decoupling sequences have shown a good performance for use in both indirect and direct dimensions [135,136]. That is despite the fact, that they have been developed in the quasi-static approximation, where rotor spinning is much slower than the frequency of the applied RF decoupling cycle. Two recently introduced rotor-synchronized sequences, smooth amplitude modulation (SAM) [137] and the $\mathrm{RN}_{n}^{v}$ family [139], can yield good proton resolution as well. The TIMES sequence [140] shows good performance at a relatively low RF field of $130 \mathrm{kHz}$. The RF irradiation alone is not designed to average out the proton-proton couplings completely for static samples in first-order approximation, but to reduce them significantly, while any remaining homonuclear interactions are further suppressed by ultra-fast MAS.

\section{Protein dynamics}

Compared to NMR in solution, solid-state NMR has the advantage that molecular internal motion can be studied in the absence of overall molecular tumbling. Indeed, the dynamics of proteins in the solid state can directly manifest itself unhindered by global molecular reorientation. Recent achievements in solidstate NMR lay the ground for studying protein dynamics with single residue resolution. The internal backbone motions of small proteins have been subsequently quantified within the frame of an extended model-free approach $[133,134]$. In general, there are two types of experiments which provide information on motion in solid-state NMR. The first approach observes spin evolution caused by relaxation and extracts the amplitude and frequency of incoherent motions. A very common example of this approach is the measurement of longitudinal relaxation [144]. In a second type of experiment, partially motionally averaged anisotropic interactions are measured and compared to their static limits which are known a priori. This approach can give only information about the amplitude of incoherent motion. One prominent example is the measurement of ${ }^{1} \mathrm{H}-{ }^{15} \mathrm{~N}$ or ${ }^{1} \mathrm{H}-{ }^{13} \mathrm{C}$ dipolar couplings and consequently dipolar order parameters [112,134,145]. Usually, the influence of incoherent motion on the spin evolution is difficult to quantify due to the presence of strong anisotropic interactions. Ultra-fast spinning can increase the accuracy of relaxation experiments and even give access to information previously not available, owing to the near-complete averaging of anisotropic interactions. At the same time, incoherent motions on timescales much faster than the MAS stay unaffected by sample rotation. So far, only few studies of protein dynamics were performed in the ultra-fast MAS regime. Employing ultrafast MAS of $60 \mathrm{kHz}$, Lewandowski and coworkers [53] could almost truncate ${ }^{13} \mathrm{C}-{ }^{13} \mathrm{C}$ PDSD during $\mathrm{T}_{1}$ measurements, performed on protonated, uniformly $\left[{ }^{13} \mathrm{C},{ }^{15} \mathrm{~N}\right]$-labeled GB1. The experiments 
provide high-accuracy information about backbone and side chain dynamics and its variation. Schanda et al. [134] obtained a vast set of relaxation parameters including ${ }^{15} \mathrm{~N} \mathrm{~T}_{1},{ }^{1} \mathrm{H}-{ }^{15} \mathrm{~N}$ order parameters, ${ }^{1} \mathrm{H}-{ }^{15} \mathrm{~N}$ dipole and ${ }^{15} \mathrm{~N}$ CSA cross-correlated relaxation rates for the backbone of highly deuterated ubiquitin at a fast MAS rate of $40-45 \mathrm{kHz}$.

\section{Conclusions}

A new generation of fast spinning MAS probe-heads has opened ways to improved resolution and sensitivity of biological solid-state NMR. Additionally, fundamentally new applications such as the study of paramagnetic metalloproteins have become feasible in the ultra-fast spinning regime. In this review, we have discussed those recent developments: the study of paramagnetic metal binding centers, new methods for resonance assignment and detection of long-range distance restraints, proton NMR at ultra-fast MAS, and the study of protein dynamics. We expect that ongoing research from an increasing number of laboratories in this still largely unexplored area of solid-state NMR will lead to even more powerful methods and exciting new applications.

\section{Acknowledgments}

We thank Dr. Antoine Loquet for discussions. Financial support by the Max Planck Society, the DFG (Emmy Noether Fellowship to A.L.), and the NSERC of Canada (Ph.D. fellowship to J.-P.D.) is gratefully acknowledged.

\section{References*}

[1] A. Lesage, Physical Chemistry Chemical Physics 11 (2009) 6876-6891.

[2] M. Renault, A. Cukkemane, M. Baldus, Angewandte Chemie-International Edition 49 (2010) 8346-8357.

[3] A. Samoson, T. Tuherm, J. Past, A. Reinhold, I. Heinmaa, T. Anupõld M.E. Smith, K.J. Pike, Fast Magic-Angle Spinning: Implications. Encyclopedia of Magnetic Resonance, John Wiley \& Sons, Ltd., 2010, pp. 1-20.

[4] D.H. Zhou, Fast Magic Angle, Spinning for Protein Solid-State NMR Spectroscopy. Encyclopedia of Magnetic Resonance, John Wiley \& Sons, Ltd., 2007 pp. 331-342.

[5*] Y. Nishiyama, Y. Endo, T. Nemoto, H. Utsumi, K. Yamauchi, K. Hioka, T. Asakura, Journal of Magnetic Resonance 208 (2011) 44-48 ${ }^{1}$.

[6] A.R. Palmer, D. Rice, S. Hafner, M. Cormos, FastMAS and UltraFastMAS (Application Note), Agilent Technologies, Inc., Santa Clara, CA, 2007.

[7] R.R. Ernst, G. Bodenhausen, A. Wokaun, Principles of Nuclear Magnetic Resonance in One and Two Dimensions, Clarendon Press, Oxford, 1994 pp. 148-157.

[8] D.I. Hoult, R.E. Richards, Journal of Magnetic Resonance 24 (1976) 71-85

[9] T.L. Peck, R.L. Magin, P.C. Lauterbur, Journal of Magnetic Resonance Series B 108 (1995) 114-124.

[10] M. Ernst, A. Detken, A. Bockmann, B.H. Meier, Journal of the American Chemical Society 125 (2003) 15807-15810.

[11] J.B.D. de Lacaillerie, B. Jarry, O. Pascui, D. Reichert, Solid State Nuclear Magnetic Resonance 28 (2005) 225-232.

[12] R. Linser, V. Chevelkov, A. Diehl, B. Reif, Journal of Magnetic Resonance 189 (2007) 209-216.

[13] A. Krahn, U. Priller, L. Emsley, F. Engelke, Journal of Magnetic Resonance 191 (2008) 78-92.

[14] F.D. Doty, J. Kulkarni, C. Turner, G. Entzminger, A. Bielecki, Journal of Magnetic Resonance 182 (2006) 239-253.

[15] S.A. McNeill, P.L. Gor'kov, J. Struppe, W.W. Brey, J.R. Long, Magnetic Resonance in Chemistry 45 (2007) S209-S220.

[16] C.V. Grant, C.H. Wu, S.J. Opella, Journal of Magnetic Resonance 204 (2010) $180-188$.

[17] J.A. Stringer, C.E. Bronnimann, C.G. Mullen, D.H.H. Zhou, S.A. Stellfox, Y. Li, E.H. Williams, C.M. Rienstra, Journal of Magnetic Resonance 173 (2005) $40-48$.

[18] B. Dillmann, K. Elbayed, H. Zeiger, M.C. Weingertner, M. Plotto, F. Engelke Journal of Magnetic Resonance 187 (2007) 10-18.

\footnotetext{
* Articles of general interest.

${ }^{1}$ Shows proton-detected ${ }^{1} \mathrm{H}-{ }^{14} \mathrm{~N}$ 2D solid-state NMR correlation spectra at $80 \mathrm{kHz}$ MAS, which is the highest MAS frequency reported so far.
}

[19] S.A. McNeill, P.L. Gor'kov, K. Shetty, W.W. Brey, J.R. Long, Journal of Magnetic Resonance 197 (2009) 135-144.

[20] G.W. Stachowiak, A.W. Batchelor, Engineering Tribology, Elsevier, ButterworthHeinemann, Amsterdam, Boston, 2005, pp. 266.

[21] A. Bockmann, C. Gardiennet, R. Verel, A. Hunkeler, A. Loquet, G. Pintacuda, L. Emsley, B.H. Meier, A. Lesage, Journal of Biomolecular NMR 45 (2009) 319-327.

[22] J. Herzfeld, A.E. Berger, Journal of Chemical Physics 73 (1980) 6021-6030.

[23] M. Ernst, A. Samoson, B.H. Meier, Chemical Physics Letters 348 (2001) 293-302.

[24] W.T. Franks, K.D. Kloepper, B.J. Wylie, C.M. Rienstra, Journal of Biomolecular NMR 39 (2007) 107-131.

[25] W.T. Franks, H.S. Atreya, T. Szyperski, C.M. Rienstra, Journal of Biomolecular NMR 48 (2010) 213-223.

[26] A. Schuetz, C. Wasmer, B. Habenstein, R. Verel, J. Greenwald, R. Riek, A. Bockmann, B.H. Meier, Chembiochem 11 (2010) 1543-1551.

[27] L.J. Sperling, D.A. Berthold, T.L. Sasser, V. Jeisy-Scott, C.M. Rienstra, Journal of Molecular Biology 399 (2010) 268-282.

[28] N.M. Szeverenyi, M.J. Sullivan, G.E. Maciel, Journal of Magnetic Resonance 47 (1982) 462-475.

[29] K. Takegoshi, S. Nakamura, T. Terao, Chemical Physics Letters 344 (2001) 631-637.

[30] C.R. Morcombe, V. Gaponenko, R.A. Byrd, K.W. Zilm, Journal of the American Chemical Society 126 (2004) 7196-7197.

[31*] I. Scholz, M. Huber, T. Manolikas, B.H. Meier, M. Ernst, Chemical Physics Letters 460 (2008) 278-2832.

[32] I. Scholz, B.H. Meier, M. Ernst, Chemical Physics Letters 485 (2010) 335-342.

[33] M. Weingarth, D.E. Demco, G. Bodenhausen, P. Tekely, Chemical Physics Letters 469 (2009) 342-348.

[34] M. Weingarth, G. Bodenhausen, P. Tekely, Chemical Physics Letters 488 (2010) 10-16.

[35] G. Hou, S. Yan, S. Sun, Y. Han, I.L. Byeon, J. Ahn, J. Concel, A. Samoson, A.M. Gronenborn, T. Polenova, Journal of the American Chemical Society 133 (2011) 3943-3953.

[36] R. Verel, M. Ernst, B.H. Meier, Journal of Magnetic Resonance 150 (2001) 81-99.

[37] A.E. Bennett, R.G. Griffin, J.H. Ok, S. Vega, Journal of Chemical Physics 96 (1992) 8624-8627.

[38] D.K. Sodickson, M.H. Levitt, S. Vega, R.G. Griffin, Journal of Chemical Physics 98 (1993) 6742-6748.

[39] M.J. Bayro, M. Huber, R. Ramachandran, T.C. Davenport, B.H. Meier, M. Ernst, R.G. Griffin, Journal of Chemical Physics 130 (2009).

[40] A. Grommek, B.H. Meier, M. Ernst, Chemical Physics Letters 427 (2006) 404-409.

[41*] V. Vijayan, J.P. Demers, J. Biernat, E. Mandelkow, S. Becker, A. Lange, ChemPhysChem 10 (2009) 2205-2208 .

[42] S. Luca, D.V. Filippov, J.H. van Boom, H. Oschkinat, H.J.M. de Groot, M. Baldus, Journal of Biomolecular NMR 20 (2001) 325-331.

[43] G. Cornilescu, F. Delaglio, A. Bax, Journal of Biomolecular NMR 13 (1999) 289-302.

[44*] J.P. Demers, V. Vijayan, S. Becker, A. Lange, Journal of Magnetic Resonance 205 (2010) 216-2234.

[45*] J.R. Lewandowski, G. De Paepe, M.T. Eddy, J. Struppe, W. Maas, R.G. Griffin, Journal of Physical Chemistry B 113 (2009) 9062-90695

[46*] M. Huber, S. Hiller, P. Schanda, M. Ernst, A. Boeckmann, R. Verel, B.H. Meier, ChemPhysChem 12 (2011) 915-918.

[47*] R. Linser, B. Bardiaux, V. Higman, U. Fink, B. Reif, Journal of the American Chemical Society 133 (2011) 5905-5912 ${ }^{6}$.

[48] P. Schanda, M. Huber, R. Verel, M. Ernst, B.H. Meier, Angewandte Chemie-International Edition 48 (2009) 9322-9325.

[49*] M. Ernst, M.A. Meier, T. Tuherm, A. Samoson, B.H. Meier, Journal of the American Chemical Society 126 (2004) 4764-47657.

[50*] M. Ernst, Journal of Magnetic Resonance 162 (2003) 1-34 ${ }^{8}$.

\footnotetext{
${ }^{2}$ Introduces the mixed rotational and rotary-resonance condition (MIRROR) which enables spin diffusion-type experiments at low RF power and high spinning frequency.

${ }^{3}$ Describes a complete set of experiments needed for the resonance assignment of proteins in the ultra-fast MAS regime.

${ }^{4}$ Presents different strategies to expand low-power cross-polarization schemes to broadband excitation.

${ }^{5}$ Demonstrates ${ }^{13} \mathrm{C}-{ }^{13} \mathrm{C}$ magnetization transfer in peptides and proteins through the Proton Assisted Recoupling (PAR) mechanism at $65 \mathrm{kHz}$ MAS.

${ }^{6}$ Both papers describe protein structure determination based on ${ }^{1} \mathrm{H}-{ }^{1} \mathrm{H}$ dipolar couplings, using deuteration and ultra-fast MAS.

${ }^{7}$ Demonstrates the use of the DREAM scheme for ${ }^{13} \mathrm{C}-{ }^{13} \mathrm{C}$ magnetization transfer in proteins. Based on a series of spectra recorded at spinning frequencies from 30 to $60 \mathrm{kHz}$, it was determined that proton decoupling is not necessary at ultra-fast MAS during DREAM transfer.

${ }^{8}$ Reviews heteronuclear decoupling techniques including low-power $c w$, TPPM, and XiX.
} 
[51] M. Ernst, A. Samoson, B.H. Meier, Journal of Magnetic Resonance 163 (2003) 332-339.

[52] M. Kotecha, N.P. Wickramasinghe, Y. Ishii, Magnetic Resonance in Chemistry 45 (2007) S221-S230.

[53] J.R. Lewandowski, J. Sein, H.J. Sass, S. Grzesiek, M. Blackledge, L. Emsley, Journal of the American Chemical Society 132 (2010) 8252-8254.

[54] M. Weingarth, G. Bodenhausen, P. Tekely, Journal of Magnetic Resonance 199 (2009) 238-241.

[55] G. Gerbaud, S. Caldarelli, F. Ziarelli, S. Gastaldi, Journal of Magnetic Resonance 210 (2011) 75-81.

[56] G. Comellas, J.J. Lopez, A.J. Nieuwkoop, L.R. Lemkau, C.M. Rienstra, Journal of Magnetic Resonance 209 (2011) 131-135.

[57] I. Bertini, L. Emsley, I.C. Felli, S. Laage, A. Lesage, J.R. Lewandowski, A. Marchetti, R. Pierattelli, G. Pintacuda, Chemical Science 2 (2011) 345-348.

[58] S. Ganapathy, A. Naito, C.A. McDowell, Journal of the American Chemical Society 103 (1981) 6011-6015.

[59] N.P. Wickramasinghe, M. Kotecha, A. Samoson, J. Past, Y. Ishii, Journal of Magnetic Resonance 184 (2007) 350-356.

[60*] N.P. Wickramasinghe, S. Parthasarathy, C.R. Jones, C. Bhardwaj, F. Long M. Kotecha, S. Mehboob, L.W.M. Fung, J. Past, A. Samoson, Y. Ishii, Nature Methods 6 (2009) 215-218

[61] P.S. Nadaud, J.J. Helmus, I. Sengupta, C.P. Jaroniec, Journal of the American Chemical Society 132 (2010) 9561-9563.

[62*] S. Laage, J.R. Sachleben, S. Steuernagel, R. Pierattelli, G. Pintacuda, L. Emsley, Journal of Magnetic Resonance 196 (2009) 133-141 ${ }^{10}$.

[63*] I. Bertini, L. Emsley, M. Lelli, C. Luchinat, J.F. Mao, G. Pintacuda, Journal of the American Chemical Society 132 (2010) 5558-5559 ${ }^{11}$.

[64] Y. Tian, L.L. Chen, D. Niks, J.M. Kaiser, J.F. Lai, C.M. Rienstra, M.F. Dunn, L.J. Mueller, Physical Chemistry Chemical Physics 11 (2009) 7078-7086.

[65] A. Lesage, Indirect Coupling and Connectivity. Encyclopedia of Magnetic Resonance, John Wiley \& Sons, Ltd., 2007, pp. 317-330.

[66] L.J. Mueller, J.J. Titman, Correlation Spectroscopy for Resonance Assignments in Solid-State Proteins using $J$-Couplings. Encyclopedia of Magnetic Resonance, John Wiley \& Sons, Ltd., 2007, pp. 297-316.

[67] M. Hohwy, C.M. Rienstra, C.P. Jaroniec, R.G. Griffin, Journal of Chemical Physics 110 (1999) 7983-7992.

[68] Y.K. Lee, N.D. Kurur, M. Helmle, O.G. Johannessen, N.C. Nielsen, M.H. Levitt, Chemical Physics Letters 242 (1995) 304-309.

[69] M. Hohwy, H.J. Jakobsen, M. Eden, M.H. Levitt, N.C. Nielsen, Journal of Chemical Physics 108 (1998) 2686-2694.

[70] M.J. Bayro, R. Ramachandran, M.A. Caporini, M.T. Eddy, R.G. Griffin, Journal of Chemical Physics 128 (2008) 11

[71] G. De Paepe, M.J. Bayro, J. Lewandowski, R.G. Griffin, Journal of the American Chemical Society 128 (2006) 1776-1777.

[72] U. Haeberlen, J.S. Waugh, Physical Review 175 (1968) 453-467.

[73*] M.H. Levitt, D.P. Raleigh, F. Creuzet, R.G. Griffin, Journal of Chemical Physics 92 (1990) 6347-636412.

[74] N.C. Nielsen, H. Bildsoe, H.J. Jakobsen, M.H. Levitt, Journal of Chemical Physics 101 (1994) 1805-1812.

[75] R. Verel, M. Baldus, M. Ernst, B.H. Meier, Chemical Physics Letters 287 (1998) 421-428.

[76] R. Verel, B.H. Meier, ChemPhysChem 5 (2004) 851-862.

[77] Q. Wang, B.W. Hu, F. Fayon, J. Trebosc, C. Legein, O. Lafon, F. Deng, J.P. Amoureux, Physical Chemistry Chemical Physics 11 (2009) 10391-10395.

[78] Q. Wang, B.W. Hu, O. Lafon, J. Trebosc, F. Deng, J.P. Amoureux, Journal of Magnetic Resonance 203 (2010) 113-128.

[79] B. Hu, L. Delevoye, O. Lafon, J. Trebosc, J.P. Amoureux, Journal of Magnetic Resonance 200 (2009) 178-188.

[80] J.R. Lewandowski, G. De Paepe, M.T. Eddy, R.G. Griffin, Journal of the American Chemical Society 131 (2009) 5769-5776.

[81] A.E. Bennett, C.M. Rienstra, J.M. Griffiths, W.G. Zhen, P.T. Lansbury, R.G. Griffin, Journal of Chemical Physics 108 (1998) 9463-9479.

[82] Y. Ishii, Journal of Chemical Physics 114 (2001) 8473-8483.

[83*] M.J. Bayro, T. Maly, N.R. Birkett, C.M. Dobson, R.G. Griffin, Angewandte Chemie-International Edition 48 (2009) 5708-5710 ${ }^{13}$.

[84] A. Pines, M.G. Gibby, J.S. Waugh, Journal of Chemical Physics 59 (1973) 569-590.

[85] E.O. Stejskal, J. Schaefer, J.S. Waugh, Journal of Magnetic Resonance 28 (1977) 105-112.

\footnotetext{
${ }^{9}$ Description of a sensitivity enhancement approach in proteins which combines doping of the sample with paramagnetic relaxation agents, ultra-fast MAS, fast recycling, and low-power RF irradiation.

${ }^{10}$ Exploits the double-quantum Hartmann-Hahn condition for low-power cross-polarization in proteins.

${ }^{11}$ Excellent application of ultra-fast spinning to the study of paramagnetic metalloproteins.

${ }^{12}$ Fundamental paper, introducing a general approach to analyze theoretically and numerically magnetization dynamics in pairs of like spins.

${ }^{13}$ Combines the use of sparse labeling and band-selective RFDR to avoid dipolar truncation and obtain long-range distance restraints.
}

[86] G. Metz, X.L. Wu, S.O. Smith, Journal of Magnetic Resonance Series A 110 (1994) 219-227.

[87] S. Hediger, B.H. Meier, N.D. Kurur, G. Bodenhausen, R.R. Ernst, Chemical Physics Letters 223 (1994) 283-288.

[88] S. Hediger, B.H. Meier, R.R. Ernst, Chemical Physics Letters 240 (1995) 449-456.

[89] S. Laage, A. Marchetti, J. Sein, R. Pierattelli, H.J. Sass, S. Grzesiek, A. Lesage, G. Pintacuda, L. Emsley, Journal of the American Chemical Society 130 (2008) 17216-17217.

[90] G. De Paepe, J.R. Lewandowski, A. Loquet, M. Eddy, S. Megy, A. Bockmann, R.G. Griffin, Journal of Chemical Physics 134 (2011) 095101-095118.

[91] M. Baldus, D.G. Geurts, S. Hediger, B.H. Meier, Journal of Magnetic Resonance Series A 118 (1996) 140-144.

[92] M. Baldus, A.T. Petkova, J. Herzfeld, R.G. Griffin, Molecular Physics 95 (1998) 1197-1207.

[93] J.R. Lewandowski, G. De Paepe, R.G. Griffin, Journal of the American Chemical Society 129 (2007) 728-729.

[94] M. Bjerring, A.B. Nielsen, Z. Tosner, N.C. Nielsen, Chemical Physics Letters 494 (2010) 326-330.

[95] P. Hodgkinson, L. Emsley, Journal of Magnetic Resonance 139 (1999) 46-59.

[96] G. De Paepe, J.R. Lewandowski, A. Loquet, A. Bockmann, R.G. Griffin, Journal of Chemical Physics 129 (2008).

[97] M. Weingarth, Y. Masuda, K. Takegoshi, G. Bodenhausen, P. Tekely, Journal of Biomolecular NMR (2011) 1-8.

[98] A. Lange, I. Scholz, T. Manolikas, M. Ernst, B.H. Meier, Chemical Physics Letters 468 (2009) 100-105.

[99] I. Scholz, B.H. Meier, M. Ernst, Chemical Physics Letters 479 (2009) 296-299.

[100] G. De Paepe, J.R. Lewandowski, R.G. Griffin, Journal of Chemical Physics 128 (2008) 26.

[101] K. Takegoshi, S. Nakamura, T. Terao, Journal of Chemical Physics 118 (2003) 2325-2341.

[102*] Y. Ishii, R. Tycko, Journal of Magnetic Resonance 142 (2000) 199-204 ${ }^{14}$

[103] A. Krushelnitsky, T. Brauniger, D. Reichert, Journal of Magnetic Resonance 182 (2006) 339-342.

[104] N. Giraud, M. Blackledge, A. Bockmann, L. Emsley, Journal of Magnetic Resonance 184 (2007) 51-61.

[105*] D.H. Zhou, J.J. Shea, A.J. Nieuwkoop, W.T. Franks, B.J. Wylie, C. Mullen, D. Sandoz, C.M. Rienstra, Angewandte Chemie-International Edition 46 (2007) $8380-8383^{15}$.

[106] A.E. McDermott, F.J. Creuzet, A.C. Kolbert, R.G. Griffin, Journal of Magnetic Resonance 98 (1992) 408-413.

[107*] J.S. Waugh, L.M. Huber, U. Haeberle, Physical Review Letters 20 (1968) $180-182^{16}$

[108] E. Brunner, D. Freude, B.C. Gerstein, H. Pfeifer, Journal of Magnetic Resonance 90 (1990) 90-99.

[109] V. Chevelkov, K. Rehbein, A. Diehl, B. Reif, Angewandte ChemieInternational Edition 45 (2006) 3878-3881.

[110*] P.K. Madhu, Solid State Nuclear Magnetic Resonance 35 (2009) 2-11 17 .

[111] J. Gottwald, D.E. Demco, R. Graf, H.W. Spiess, Chemical Physics Letters 243 (1995) 314-323.

[112] J.L. Lorieau, A.E. McDermott, Journal of the American Chemical Society 128 (2006) 11505-11512.

[113] V. Chevelkov, K. Faelber, A. Diehl, U. Heinemann, H. Oschkinat, B. Reif, Journal of Biomolecular NMR 31 (2005) 295-310.

[114] M.M. Maricq, J.S. Waugh, Journal of Chemical Physics 70 (1979) 3300-3316

[115] S. Ray, E. Vinogradov, G.J. Boender, S. Vega, Journal of Magnetic Resonance 135 (1998) 418-426.

[116] C. Filip, S. Hafner, I. Schnell, D.E. Demco, H.W. Spiess, Journal of Chemical Physics 110 (1999) 423-440.

[117] V. Chevelkov, B. Reif, Concepts in Magnetic Resonance Part A 32A (2008) 143-156.

[118] G.P. Holland, B.R. Cherry, J.E. Jenkins, J.L. Yarger, Journal of Magnetic Resonance 202 (2010) 64-71.

[119*] A. Samoson, T. Tuherm, Z. Gan, Solid State Nuclear Magnetic Resonance 20 (2001) $130-136^{18}$.

[120] D.H. Zhou, D.T. Graesser, W.T. Franks, C.M. Rienstra, Journal of Magnetic Resonance 178 (2006) 297-307.

[121] V.E. Zorin, S.P. Brown, P. Hodgkinson, Journal of Chemical Physics 125 (2006).

[122] V.E. Zorin, B. Elena, A. Lesage, L. Emsley, P. Hodgkinson, Magnetic Resonance in Chemistry 45 (2007) S93-S100.

\footnotetext{
${ }^{14}$ One of the first works that demonstrates the efficiency of ${ }^{1} \mathrm{H}$ indirect detection in 2D spectroscopy of solids at high MAS rates.

${ }^{15}$ First 3D structure of a small deuterated protein obtained by MAS NMR employing proton detection and proton-proton dipolar couplings for distance restraints.

${ }^{16}$ Introduces a concept of multi-pulse RF irradiation for proton-proton homonuclear decoupling and high-resolution proton spectroscopy.

17 Comprehensive review highlighting principles of major proton-proton decoupling sequences under MAS.

18 Systematic study of line-width and sensitivity in proton-detected experiments at different experimental conditions.
} 
[123] D.H. Zhou, C.M. Rienstra, Angewandte Chemie-International Edition 47 (2008) 7328-7331.

[124] D.H. Zhou, G. Shah, C. Mullen, D. Sandoz, C.M. Rienstra, Angewandte Chemie-International Edition 48 (2009) 1253-1256.

[125] E.K. Paulson, C.R. Morcombe, V. Gaponenko, B. Dancheck, R.A. Byrd, K.W. Zilm, Journal of the American Chemical Society 125 (2003) 15831-15836.

[126*] D.H. Zhou, G. Shah, M. Cormos, C. Mullen, D. Sandoz, C.M. Rienstra, Journal of the American Chemical Society 129 (2007) 11791-11801 ${ }^{19}$

[127] M. Carravetta, Y. Murata, M. Murata, I. Heinmaa, R. Stern, A. Tontcheva, A. Samoson, Y. Rubin, K. Komatsu, M.H. Levitt, Journal of the American Chemical Society 126 (2004) 4092-4093.

[128] K. Liu, D. Ryan, K. Nakanishi, A. McDermott, Journal of the American Chemical Society 117 (1995) 6897-6906.

[129] N.P. Wickramasinghe, M. Shaibat, Y. Ishii, Journal of the American Chemical Society 127 (2005) 5796-5797.

[130] D.A. Torchia, A. Szabo, Journal of Magnetic Resonance 64 (1985) 135-141.

[131] A.G. Palmer, J. Williams, A. McDermott, Journal of Physical Chemistry 100 (1996) 13293-13310.

[132] A.G. Palmer, C.D. Kroenke, J.P. Loria, Nuclear Magnetic Resonance of Biological Macromolecules, Part B 339 (2001) 204-238.

[133] V. Chevelkov, U. Fink, B. Reif, Journal of Biomolecular NMR 45 (2009) 197-206.

[134] P. Schanda, B.H. Meier, M. Ernst, Journal of the American Chemical Society 132 (2010) 15957-15967.

[135] E. Salager, J.N. Dumez, R.S. Stein, S. Steuernagel, A. Lesage, B. Elena-Herrmann, L. Emsley, Chemical Physics Letters 498 (2010) 214-220.

[136] M. Leskes, S. Steuernagel, D. Schneider, P.K. Madhu, S. Vega, Chemical Physics Letters 466 (2008) 95-99.

[137] J.P. Amoureux, B. Hu, J. Trebosc, Journal of Magnetic Resonance 193 (2008) 305-307.

[138] M. Leskes, P.K. Madhu, S. Vega, Journal of Magnetic Resonance 199 (2009) 208-213.

[139] S. Paul, D. Schneider, P.K. Madhu, Journal of Magnetic Resonance 206 (2010) 241-245.

[140] Z.H. Gan, P.K. Madhu, J.P. Amoureux, J. Trebosc, O. Lafon, Chemical Physics Letters 503 (2011) 167-170.

[141] M. Lee, W.I. Goldburg, Physical Review 140 (1965) 1261-1271.

[142] E. Vinogradov, P.K. Madhu, S. Vega, Chemical Physics Letters 314 (1999) $443-450$.

[143] D. Sakellariou, A. Lesage, P. Hodgkinson, L. Emsley, Chemical Physics Letters 319 (2000) 253-260.

[144] D.A. Torchia, A. Szabo, Journal of Magnetic Resonance 49 (1982) 107-121.

[145] V. Chevelkov, U. Fink, B. Reif, Journal of the American Chemical Society 131 (2009) 14018-14022.

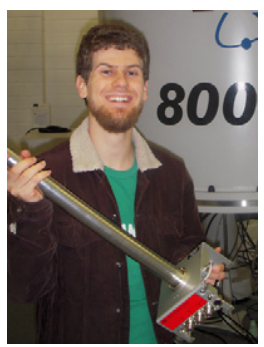

Jean-Philippe Demers received his B.Sc. in Biochemistry (honours) from McGill University, Montréal (2006). He completed a M.Sc. in Chemistry at McGill (2008) under the supervision of Dr. Anthony Mittermaier, on the topic of protein-peptide interaction studied by NMR and ITC. In 2009, he joined the research group of Dr. Adam Lange at the Max Planck Institute for Biophysical Chemistry (MPIbpc) to pursue a Ph.D. in Physics at the Georg-August Universität Göttingen. J.-P.D. is interested in NMR methodology development and in the study of proteins and inorganic materials.

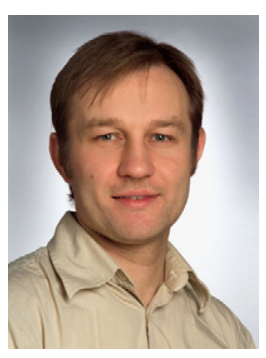

Veniamin Chevelkov is currently a Postdoctoral Fellow at the MPIbpc, Göttingen. Previously he was working as a Postdoctoral Fellow at Purdue University, Indiana and the Forschunginstitut für Molekulare Pharmakologie, Berlin, where he also obtained a Ph.D. degree in Biophysics. His main research interests are method development and the study of protein dynamics using MAS solid state NMR.

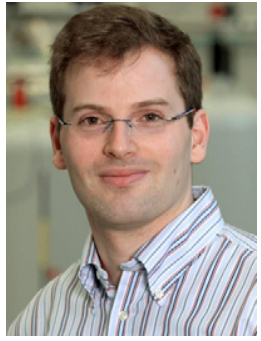

Adam Lange studied physics in Göttingen and received his Ph.D. in 2006 at the MPIbpc in cooperation with the NIH in Bethesda (Maryland, USA). Subsequently, he moved to the ETH Zürich with an EMBO Fellowship. Since 2008, he has headed the Solid-State NMR Spectroscopy Research Group at the MPIbpc. In 2006, Adam Lange was awarded the Otto Hahn Medal of the Max Planck Society and the Ernst Prize of the German Chemical Society. Since 2009, Adam Lange has been supported by the DFG within the Emmy Noether Program.

${ }^{19}$ Systematic study of proton line-width at $40 \mathrm{kHz}$ MAS in a fully protonated protein and a model compound at different external magnetic fields. 